Brazilian Journal

of Chemical

Engineering

\title{
A METHODOLOGY TO OBTAIN ANALYTICAL MODELS THAT REDUCE THE COMPUTATIONAL COMPLEXITY FACED IN REAL TIME IMPLEMENTATION OF NMPC CONTROLLERS
}

\author{
Leonardo D. Ribeiro ${ }^{1 *}$ and Argimiro R. Secchi ${ }^{1}$ \\ ${ }^{1}$ Universidade Federal do Rio de Janeiro, Programa de Engenharia Química, Rio de Janeiro, RJ, Brasil. E-mail: 1dorigo@peq.coppe.ufrj.br - \\ ORCID: 0000-0002-2215-4831; arge@peq.coppe.ufrj.br - ORCID: 0000-0001-7297-3571
}

(Submitted: October 03, 2018 ; Revised: November 06, 2018 ; Accepted: January 06, 2019)

\begin{abstract}
Model Predictive Control, MPC and NMPC, and real-time optimization, RTO and D-RTO, are known to help plant operability through the mitigation of impacts caused by external disturbances. However, the usage of these tools in industry requires overcoming some challenges, for instance: accurate models of the process, particularly in regard to nonlinearities; suitable computational time for obtaining the solution of large-scale problems and model mismatch between the RTO or D-RTO and NMPC. In this paper, we present a methodology to obtain analytical model predictions based on a Hammerstein structure to represent the process nonlinearities, reducing the computational effort in real-time applications. Unlike most common approaches that transform NMPC internal models, described by differential-algebraic equations (DAE), into an approximate system of nonlinear algebraic (NLA) equations using, for instance, orthogonal collocation, in the proposed approach, the obtained NLA is an exact description of the original DAEs system. The proposed algorithm was applied to a non-isothermal CSTR (continuous stirred tank reactor) integrated with an optimization layer. The results show that the proposed structure presented a significant reduction in computational time without performance loss, when compared with the NMPC using a rigorous model. Moreover, the proposed strategy demonstrated good performance in tracking the targets sent by the optimization layer, without model mismatches between layers.

Keywords: NMPC; RTO; D-RTO; CSTR.
\end{abstract}

\section{INTRODUCTION}

MPC is an optimization-based control strategy which is well suited for multivariable processes with constraints. Constraints satisfaction is a very important advantage of MPC algorithms because constraints usually determine product quality, environmental impact and process safety. When the process presents nonlinear behavior, the MPC algorithms using a linear model may not present an acceptable performance. In this case, NMPC algorithms based on nonlinear models should be investigated (Henson, 1998). As any MPC strategy, a dynamic model of the process is used for prediction, and the choice of the nonlinear model structure is extremely important for the success of the controller.
In an NMPC algorithm, a nonlinear optimal control problem is solved at each sampling instant, spending a significant computational time. Therefore, the most difficult issue to implement NMPC algorithms in industrial applications is the computational time needed to robustly solve large-scale optimizations without feedback delays that can degrade the performance and possibly cause dangerous instabilities in the process. This challenge led to the development of efficient nonlinear programming (NLP) to solve complex control problems for industrial application. $\mathrm{Li}$ and Biegler (1989) were the first to represent a nonlinear dynamic model by successive linear models around a nominal trajectory, where a quadratic programming $(\mathrm{QP})$ is solved at every sampling time. Diehl et al.

\footnotetext{
* Corresponding author: Leonardo D. Ribeiro - E-mail: 1dorigo@peq.coppe.ufrj.br
} 
(2005) proposed a real-time iteration scheme, where only one Newton or QP iteration of the NLP is solved online at each sampling time, demonstrating robustness and satisfactory real-time performance in a numerical experiment. In order to reduce the computational time, there are algorithms based on sensitivity analysis. Zavala and Biegler (2009) proposed an algorithm which exploits the parametric property of the Optimal Control Problem (OCP) and approximates the true optimal solution using NLP sensitivity concepts. Pirnay et al. (2012) presented a study showing a capability for sensitivity analysis that is coupled to the IPOPT algorithm, a barrier NLP solver with a filterbased line search. Yang and Biegler (2013) solved the NLP problem offline one-step in advance, where the NLP sensitivity is used to get the manipulated variables online with the actual measurement, and Lopez-Negrete et al. (2013) applied this strategy to two large-scale processes. Recently, Biegler et al. (2015) showed an efficient NLP sensitivity tool that required 2-3 orders of magnitude less computation time than the traditional NLP solution.

Alangar et al. (2015a) proposed a nonlinear system identification technique to obtain well-conditioned polynomial nonlinear state-space (PNLSS) models. The PNLSS model can be correctly integrated with large time steps without significant performance loss, reducing the computational effort. The wellconditioned nonlinear models enable the design of a Lyapunov-based Economic model Predictive control (LEMPC), demonstrating closed-loop stability in the presence of computational delay and process noise. There is a variety of papers on EMPC performance, such as stability, computation time reduction and improving the closed-loop economic performance compared to the economic performance at the economically optimal steady state (Alangar et al., 2015b; Ellis and Christofides, 2015). The proposed LEMPC was applied in a continuously stirred tank reactor (CSTR), illustrating computational advantages without significant reduction in profit, when compared with models based on first-principles.

Fast update methods developed for direct solution approaches can be classified in the suboptimal update methods and in the sensitivity-based update methods. The choice of a fast NMPC strategy is not trivial because the methods have similar structures. Inga and Marquardt (2016) presented a review and assessed the common elements of the fast NMPC, including fast update methods and the control structure applied in these schemes.

Eaton et al. (2017) introduced a method for using high fidelity simulators in NMPC by implementing a switched control scheme. In this strategy, when the linear model prediction error exceed a tolerance, the algorithm started a re-identification using simulated data in the current operating conditions. While the model identification is calculated, the switched control calls a low order NMPC that uses a reduced order observer model (Stamnes et al., 2008) to keep the process in control.

Aiming to reduce the online computational demands, Khani and Haeri (2015) proposed an algorithm that represents nonlinear processes with uncertain linear models and thus the nonlinear control problem is converted into a robust MPC (RMPC) problem. However, while the RMPC reduces the computational effort, it leads to a suboptimal solution.

Linear approximation of the nonlinear model used in NMPC algorithms is a common strategy to solve nonlinear optimization problem. Trierweiler and Secchi (2000) proposed an NMPC based on local linear model networks to represent nonlinear systems. This approach was used by Duraiski et al. (2001) to design an NMPC controller with a Local Linearization on the Trajectory (LLT) algorithm. The method minimizes the objective function using a nonlinear model through successive linearizations until convergence of the control movements. Different model structures can be used to represent the process, such as the identified input-output nonlinear model, first-principles model, and local model network. The algorithm showed high performance when applied to control nonlinear systems. In this context, Lawrynczuk (2013) proposed three linearizations strategies to solve the NLP problem, the first is simplified linearization around the current operation point (MPC-NPSL), the second consists in computing the prediction with a nonlinear model and apply a linearization along the trajectory once at each sampling instant (MPC-NPLT), and the last one is an algorithm with Nonlinear Prediction and Linearization along the Predicted Trajectory (MPC-NPLPT), the output trajectory calculation and linearization along the computed input trajectory being carried out in an iterative way. In all strategies the neural Wiener model is used to calculate the nonlinear predicted trajectory and the linear approximation allows one to solve the control problem as a quadratic programming problem. The disadvantage of MPC algorithms with successive linearization is the approximation accuracy that affects the control performance.

Rashid et al. (2016) proposed a data-driven multimodel approach weighting scheme to represent the nonlinear nature of an electric arc furnace process. However, the strategy had difficulties to find a weighting function and to get data from identification.

Other challenges for industrial implementation of NMPC strategies are the plant-model mismatch and unmeasured disturbances that can lead to performance loss or constraint violations. The multi-stage NMPC is a robust NMPC approach based on the assumption that uncertainty can be modeled by a scenario tree 
and solved in an efficient way, both in terms of computational time and memory requirements (Marti et al., 2015). The challenge is to build the scenario tree, considering the uncertainty space, which can greatly increase the size of the optimization problem, especially for large prediction horizons.

In this work, a nonlinear approach to describe the process that makes NMPC less computationally demanding and suitable for real-time application was proposed. Moreover, the proposed NMPC was integrated with an optimization layer, without model mismatches between layers that could cause infeasibility problems to the controller to follow the optimal reference trajectory from the DRTO or to track an optimal steady state from the RTO.

In the next section, the methodology to obtain the analytical model to represent the nonlinear system is presented and the structure of the proposed algorithm. In Section 3, cases studies and analyses of the proposed nonlinear model predictive control (NMPC) together with the optimization algorithm are carried out.

\section{PROPOSED METHOTOLOGY}

In this section, we describe the proposed methodology to develop an NMPC with fast computational structure and integrated with the optimization layer.

\section{Formulation of the control problem}

The NMPC is based on the solution of a discrete nonlinear optimal control problem (NOCP), which is formulated as:

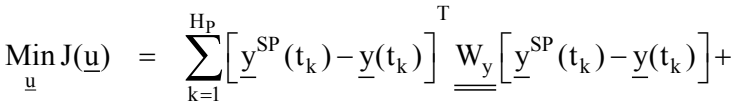

$$
\begin{aligned}
& +\sum_{\mathrm{k}=1}^{\mathrm{H}_{\mathrm{C}}}\left[\underline{\Delta u}^{\mathrm{T}}\left(\mathrm{t}_{\mathrm{k}}\right) \underline{\underline{\mathrm{R}}} \underline{\underline{\mathrm{u}}}\left(\mathrm{t}_{\mathrm{k}}\right)\right]+ \\
& +\sum_{\mathrm{k}=1}^{\mathrm{H}_{\mathrm{C}}}\left[\underline{\underline{u}}^{\mathrm{SP}}\left(\mathrm{t}_{\mathrm{k}}\right)-\underline{\mathrm{u}}\left(\mathrm{t}_{\mathrm{k}}\right)\right]^{\mathrm{T}} \underline{\underline{\mathrm{R}_{\mathrm{u}}}}\left[\underline{\underline{u}}^{\mathrm{SP}}\left(\mathrm{t}_{\mathrm{k}}\right)-\underline{\mathrm{u}}\left(\mathrm{t}_{\mathrm{k}}\right)\right] \\
& \underline{y}\left(t_{k}\right)=f^{N L}\left(\underline{u}\left(t_{k}\right), \underline{d}\left(t_{k}\right), \underline{y}\left(t_{0}\right), t_{k}\right), \quad t_{k} \in\left[t_{1}, t_{k}\right] \\
& \left.\underline{\mathrm{u}}_{\min } \leq \underline{\mathrm{u}}_{(\mathrm{t}}\right) \leq \underline{\mathrm{u}}_{\max } \\
& \underline{\mathrm{y}}_{\min } \leq \underline{\mathrm{y}}\left(\mathrm{t}_{\mathrm{k}}\right) \leq \underline{\mathrm{y}}_{\max }
\end{aligned}
$$

where $H_{P}$ is the prediction horizon, $H_{C}$ is the control horizon, $W_{y}$ is the positive semi-definite diagonal matrix of controlled variable weighting factors, $R_{u}$ is the positive semi-definite diagonal matrix of manipulated target weighting factors, $\mathrm{R}$ is the positive semi-definite diagonal matrix of the control move suppression factors, $u^{S P}$ and $y^{S P}$ are the manipulated and controlled target, respectively, from the optimization layer, $\underline{u}\left(t_{k}\right) \in \mathfrak{R}^{n_{u}}$ and $\underline{d}\left(t_{k}\right) \in \mathfrak{R}^{n_{d}}$ are control and disturbance signals, respectively, with $\underline{u}\left(t_{k}\right)$ described by a piecewise constant functional. In this paper, all disturbances are considered to be measured, but sometimes in industrial plants important disturbances are unmeasured. In this case, the use of Kalman filtering techniques (Huang et al., 2012) can estimate the effects of these disturbances in controlled variables, $y\left(t_{k}\right)$. The nonlinear model is described in the next section.

Equations 1 to 4 describe the NMPC formulation, where Equation 2 is the main novelty, with an analytical internal model, formulated later as Equations 6 to 9, to describe the process dynamic behavior. In order to compare this proposed structure with the best possible performance, another NMPC with the internal model replaced by the DAEs system that describes the plant behavior, Equation 5, was solved too, providing a reference solution.

$\mathrm{F}\left(\underline{\dot{x}}\left(\mathrm{t}_{\mathrm{k}}\right), \underline{\mathrm{x}}\left(\mathrm{t}_{\mathrm{k}}\right), \underline{\mathrm{y}}\left(\mathrm{t}_{\mathrm{k}}\right), \underline{\mathrm{u}}\left(\mathrm{t}_{\mathrm{k}}\right), \mathrm{t}_{\mathrm{k}}\right)=0, \quad \mathrm{x}\left(\mathrm{t}_{0}\right)=\mathrm{x}_{0} ; \mathrm{t}_{\mathrm{k}} \in\left[\mathrm{t}_{0}, \mathrm{t}_{\mathrm{n}}\right]$

where $F(\bullet) \in \mathfrak{R}^{\mathrm{n}_{\mathrm{x}}+\mathrm{n}_{\mathrm{y}}}$ is the DAE system, $\underline{x}\left(t_{k}\right) \in \mathfrak{R}^{n_{x}}$ are the state variables, $y\left(t_{k}\right) \in \mathfrak{R}^{n_{y}}$ are the controlled variables and $\underline{u}\left(t_{k}\right) \in \mathfrak{R}^{n_{u}}$ are the manipulated variables. Both NLP problems were solved by the interior point method (Biegler, 2010), with an important difference between the proposed model and the reference solution, where the NMPC internal model described by the system is numerically integrated or transformed into NLA equations by discretization techniques, such as orthogonal collocation on finite elements, in the latter. In the proposed approach, the resulting NLA equations are an exact description of the original DAEs system, it being possible to analytically compute the exact gradient and Hessian, which makes it faster to solve the NLP problem.

\section{Determination of the nonlinear model}

The challenge in implementing NMPC techniques is the development of models that represent the process without spending a lot of computational time. This step is very important because the controller performance depends on how capable the model is in describing the plant behavior. There are many nonlinear models in the literature that can be used in NMPC algorithms, such as black-box models (Nonlinear Auto Regressive with external input (NARX) polynomial model (Sriniwas and Arkun, 1997)), fuzzy models (Tatjewski, 2007), Volterra models (Doyle et al., 1995), artificial neural network models (Akesson and Toivonen, 2006), etc.), first-principles models (Rodriguez and Perez, 2005) and gray-box models (Pearson and Pottmann, 2000). Hammerstein and Wiener models are well-known and widely-used nonlinear models in the literature (Janczak, 
2004). These models have a block-oriented structure, composed of a linear block that represents the dynamic behavior and another block that maps the nonlinear steady states of the process. Therefore, they can be applied with different nonlinear control techniques, for instance, adaptive control (Knohl and Unbehauen, 2000), model reference adaptive control (Pajunen, 1992), Internal Model Control (IMC) (Norquay et al., 1998, 1999), linearizing feedforward-feedback control (Kalafatis et al., 2005) and MPC. There is an important advantage in the MPC strategies, the steady-state part of the model can compensate the nonlinearity of the process (Bloemen et al., 2001; Cervantes et al., 2003a; Gómez et al., 2004; Lawrynczuk, 2010; Peng et al., 2011). An approach to solve a NMPC is to transform it into an adaptive MPC. This strategy consists in multiplying the linear dynamic part of the model by the current "gain" of the steady-state part which is computed online (Seyab and Cao, 2006), resulting in a linear model to be used in a classical linear MPC algorithm.

In this work, a multi-parametric approach to represent the non-linearities of the process was proposed. However, many others structures can be used in Equation 2, such as a continuous piecewise linear function (Cervantes et al., 2003b), cubic spline (Norquay et al., 1999), wavelets (Aadaleesan et al., 2008), linear combinations of basis functions (Gomes et al., 2004) and artificial neural networks (Lawrynczuk, 2007).

Equation 6 shows the proposed model used to represent the process, where Equation 7 is a multiparametric structure to represent the steady-state conditions, see Appendix A, and Equation 9 is an analytical structure to represent the dynamic behavior, see Appendix B. The NMPC algorithm based on the proposed analytical model to solve the NLP problem was also compared with the adaptive MPC approach described above.

$$
\begin{aligned}
& \underline{y}^{(t)}=\underline{y}^{0}+\left[\underline{y}^{s s}(\underline{u}, \underline{d})-\underline{y}^{0}\right] \otimes \underline{f}(\mathrm{t}) \\
& y_{j}^{S S}(\underline{u}, \underline{d})=\prod_{k=1}^{n_{u}} \sum_{i=0}^{n_{1}} C_{i, k, j}(\underline{d})\left(u_{k}\right)^{i} \\
& C_{i, k, j}(\underline{d})=\prod_{1=1}^{n_{d}} \sum_{m=0}^{n_{2}} \alpha_{i, k, j, m, 1}\left(d_{1}\right)^{m} \\
& f(t)=1-\exp \left[\frac{-\varepsilon_{j}\left(t-\tau_{d_{j}}\right)}{\tau_{d_{j}}}\right] \times \\
& \quad \times\left\{\cosh \left[\frac{\sqrt{\varepsilon_{j}^{2}-1}}{\tau_{j}}\left(t-\tau_{d_{j}}\right)\right]+\frac{\varepsilon_{j}}{\sqrt{\varepsilon_{j}^{2}-1}} \sinh \left[\frac{\sqrt{\varepsilon_{j}^{2}-1}}{\tau_{j}}\left(t-\tau_{d_{j}}\right)\right]\right\}
\end{aligned}
$$

where $j=1, \ldots, n_{y}, C_{i, k, j}$ and $\alpha_{i, k, j, m, l}$ are the parameters of the polynomial models of degrees $n_{1}$ and $n_{2}$, respectively, $\otimes$ is the Hadamard product (Appendix C), $y(t) \in \mathfrak{R}^{n_{y}}$ are the controlled variables, $\underline{d}^{0} \in \mathfrak{R}^{n_{y}}$ are the initial values of the controlled variables, $y^{S S}$ : $\mathfrak{R}_{u}{ }^{n} \times \mathfrak{R}_{d}{ }^{n} \rightarrow \mathfrak{R}_{v}{ }^{n}$ represents the steady-state mapping from inputs to outputs, while $f(t) \in \mathfrak{R}^{n_{y}}$ describes the dynamic behavior of the process. The structure of Equation 6 allows getting the gradient and the Hessian analytically, reducing the computational effort to obtain the NLP solution.

The methodology used to get the model described in Equations 6 to 9 was twofold: (1) Structure selection to find the more appropriate function that describes the dynamic behavior of the process through identification tests, using first and second order functions, with and without dead time, that minimizes the sum of square errors calculated by difference between the plant and the model in each instant, Equation 10. (2) A multiparametric function was proposed to represent the non-linearity of the steady states, where only steadystate data were used to obtain the parameters, and a test procedure was applied to determine the input sequence to get data that describe the process non-linearities.

$$
\underset{\underline{\underline{\theta}}}{\arg \min } \sum_{\mathrm{k}=1}^{\mathrm{n}}\left(\operatorname{Error}\left(\mathrm{t}_{\mathrm{k}}\right)\right)^{2}
$$

$\operatorname{Error}\left(\mathrm{t}_{\mathrm{k}}\right)=\mathrm{y}\left(\mathrm{t}_{\mathrm{k}}\right)-\mathrm{y}\left(\mathrm{t}_{\mathrm{k}}\right), \quad \mathrm{t}_{\mathrm{k}} \in\left[\mathrm{t}_{1}, \mathrm{t}_{\mathrm{n}}\right]$

where $\underline{\theta}$ are the model parameters, $y \in \mathfrak{R}^{n_{y}}$ are the model variables and $y^{P} \in \mathfrak{R}^{n_{y}}$ are the plant variables.

Nonlinear model identification is a challenge, because of the possible non-convex optimization problem to be solved, imposing difficulties to find the globally optimal solution. Thus, to obtain a robust solution of the problem, the following three-step identification strategy was proposed: (1) Carry out an identification with linear models to get an initial estimate for the parameters of the linear dynamic model; (2) With only steady-state data, estimate the parameters of the steady-state nonlinear model; (3) Estimate the parameters of the dynamic linear model, (Appendix B), coupled with the nonlinear model obtained in the previous step, using as initial estimate the solution of the identification of the first step.

\section{Integration of the NMPC with the optimization layer}

Optimization techniques have many challenges, especially when applied in real time. For instance, one of the most important is the integration between the optimization and control layers, because the models, in general, are different; the first uses phenomenological models and the second usually uses empirical models. 
This fact may lead to unreachable targets for the control layer. In this context, many authors have proposed an intermediate feasibility optimization layer, in which new targets are evaluated, using the static part of the empirical models of the controller (Zanin et al., 2000). In this intermediate optimization, the sum of the square of the deviations between the targets of this layer and the optimization layer is minimized. The targets calculated in the intermediate layer are reachable by the controller, because they were obtained using the same empirical model. Therefore, there is no guarantee that this optimal point is the same from the optimization layer with phenomenological models, resulting in suboptimal points.

In the proposed approach, the static part of the nonlinear model of the controller can map the entire optimization region built-up with rigorous models of the process, avoiding the necessity of an intermediate layer to integrate the optimization and control layers. The mathematical formulation of optimization layer is illustrated in Equations 12 to 15.

$$
\left\{\mathrm{y}^{\mathrm{A}}, \mathrm{u}^{\mathrm{A}}\right\}=\underset{\underline{\mathrm{y}}\left(\mathrm{t}_{\mathrm{n}}\right), \underline{\mathrm{u}}\left(\mathrm{t}_{\mathrm{n}}\right), \mathrm{d}\left(\mathrm{t}_{\mathrm{n}}\right)}{\arg \min } \varphi\left(\mathrm{t}_{\mathrm{n}}\right)
$$

s.t.

$$
\begin{aligned}
& \underline{y}\left(\mathrm{t}_{\mathrm{n}}\right)=\underline{\mathrm{y}}^{\mathrm{ss}}\left(\underline{\mathrm{u}}\left(\mathrm{t}_{\mathrm{n}}\right), \underline{\mathrm{d}}\left(\mathrm{t}_{\mathrm{n}}\right)\right) \\
& \mathrm{y}^{\mathrm{L}} \leq \underline{\mathrm{y}}\left(\mathrm{t}_{\mathrm{n}}\right) \leq \mathrm{y}^{\mathrm{U}} \\
& \mathrm{u}^{\mathrm{L}} \leq \underline{\mathrm{u}}\left(\mathrm{t}_{\mathrm{n}}\right) \leq \mathrm{u}^{\mathrm{U}}
\end{aligned}
$$

where $\phi\left(t_{n}\right)$ is the objective function, $y^{S S}\left(\underline{u}\left(t_{n}\right), \underline{d}\left(t_{n}\right)\right)$ $\in \mathfrak{R}^{n_{y}}$ is the multi-parametric model to describe the steady state, $\underline{d}\left(t_{n}\right) \in \mathfrak{R}^{n} d$ are the disturbance variables, $\underline{y}\left(t_{n}\right) \in \mathfrak{R}^{n_{y}}$ are the controlled variables and $\underline{u}\left(t_{n}\right) \in \mathfrak{R}^{n_{u}}$ are the manipulated variables. The optimal solution of the optimization problem is $\underline{\underline{x}}^{A} \in \mathfrak{R}^{n_{y}}$ and $\underline{u}^{A} \in \mathfrak{R}^{n_{u}}$.

Equations 16 to 19 show the rigorous optimization layer using phenomenological models to represent the process. The formulation is similar to the above problem, but replacing the proposed model, Equation 13 , by rigorous model.

$$
\begin{aligned}
& \left\{\mathrm{y}^{\mathrm{R}}, \mathrm{u}^{\mathrm{R}}\right\}=\underset{\underline{\mathrm{y}}\left(\mathrm{t}_{\mathrm{n}}\right), \underline{\underline{a}}\left(\mathrm{t}_{\mathrm{n}}\right), \underline{\mathrm{d}}\left(\mathrm{t}_{\mathrm{n}}\right)}{\arg \min } \varphi\left(\mathrm{t}_{\mathrm{n}}\right) \\
& \mathrm{F}\left(\underline{\mathrm{x}}\left(\mathrm{t}_{\mathrm{n}}\right), \underline{\mathrm{y}}\left(\mathrm{t}_{\mathrm{n}}\right), \underline{\mathrm{u}}\left(\mathrm{t}_{\mathrm{n}}\right), \underline{\mathrm{d}}\left(\mathrm{t}_{\mathrm{n}}\right)\right)=0 \\
& \mathrm{y}^{\mathrm{L}} \leq \underline{\mathrm{y}}(\mathrm{t}) \leq \mathrm{y}^{\mathrm{U}} \\
& \mathrm{u}^{\mathrm{L}} \leq \underline{\mathrm{u}}\left(\mathrm{t}_{\mathrm{n}}\right) \leq \mathrm{u}^{\mathrm{U}}
\end{aligned}
$$

where $\phi\left(t_{n}\right)$ is the objective function, $F(\bullet) \in \mathfrak{R}^{\mathrm{n}_{\mathrm{x}}+\mathrm{n}_{\mathrm{y}}}$ is the algebraic equation system, $\underline{x}\left(t_{n}\right) \in \mathfrak{R}^{n_{x}}$ are the state variables, $\underline{d}\left(t_{n}\right) \in \mathfrak{R}^{n d}$ are the disturbance variables, $y(t) \in \mathfrak{R}^{n_{y}}$ are the controlled variables and $\underline{u}\left(t_{n}\right) \in \mathfrak{R}^{n_{u}}$ are the manipulated variables. The optimal solution of the optimization problem using the rigorous model is $y^{R} \in \mathfrak{R}^{n_{y}}$ and $\underline{u}^{R} \in \mathfrak{R}^{n_{u}}$.

Equations 20 to 23 show the intermediate optimization layer.

$$
\left.\left\{\mathrm{y}^{\mathrm{I}}, \mathrm{u}^{\mathrm{I}}\right\}=\underset{\underline{\mathrm{y}}\left(\mathrm{t}_{\mathrm{n}}\right), \underline{\mathrm{u}}\left(\mathrm{t}_{\mathrm{n}}\right), \underline{\mathrm{d}}\left(\mathrm{t}_{\mathrm{n}}\right)}{\arg \min }\left(\mathrm{t}_{\mathrm{n}}\right)-\underline{\mathrm{y}}^{\mathrm{R}}\left(\mathrm{t}_{\mathrm{n}}\right)\right)^{2}
$$

s.t

$$
\begin{aligned}
& \underline{\mathrm{y}}\left(\mathrm{t}_{\mathrm{n}}\right)=\underline{\mathrm{y}}^{\mathrm{ss}}\left(\underline{\mathrm{u}}\left(\mathrm{t}_{\mathrm{n}}\right), \underline{\mathrm{d}}\left(\mathrm{t}_{\mathrm{n}}\right)\right) \\
& \mathrm{y}_{\min } \leq \underline{\mathrm{y}}\left(\mathrm{t}_{\mathrm{n}}\right) \leq \mathrm{y}_{\max } \\
& \mathrm{u}_{\min } \leq \underline{\mathrm{u}}\left(\mathrm{t}_{\mathrm{n}}\right) \leq \mathrm{u}_{\max }
\end{aligned}
$$

where $y^{S S}\left(\underline{u}\left(t_{n}\right), \underline{d}\left(t_{n}\right)\right) \in \mathfrak{R}^{n_{y}}$ is the multi-parametric model to describe the steady state, $\underline{d}\left(t_{n}\right) \in \mathfrak{R}^{n} d$ are the disturbance variables, $y\left(t_{n}\right) \in \mathfrak{R}^{n_{y}}$ are the controlled variables and $\underline{u}\left(t_{n}\right) \in \mathfrak{R}^{n_{u}}$ are the manipulated variables. The optimal solution of the intermediate optimization layer is $\underline{y}^{I} \in \mathfrak{R}^{n_{y}}$ and $\underline{u}^{I} \in \mathfrak{R}^{n_{u}}$. Equation 24 illustrates the integration between the optimization and control layers when there is an intermediate optimization layer. On the other side, in the proposed approach the integration is represented by Equation 25 with $y^{4}\left(t_{n}\right)$ sent directly to the control layer.

$$
\begin{aligned}
& \underline{y}^{S P}\left(t_{k}\right)=\underline{y}^{I}\left(t_{n}\right), \quad t_{k} \in\left[t_{0}, t_{n}\right] \\
& \underline{y}^{S P}\left(t_{k}\right)=\underline{y}^{A}\left(t_{n}\right) \cong \underline{y}^{R}\left(t_{n}\right), \quad t_{k} \in\left[t_{0}, t_{n}\right]
\end{aligned}
$$

The challenge to apply optimization techniques with static models is to ensure that the plant is in a steady state, as this condition is crucial to a successful optimization. In this context, there are several works questioning whether steady-state optimization is the best way. Since the control layer has no information about the dynamic economical performance of the plant, it may generate trajectories that simply track a suboptimal setpoint (Jaschke et al., 2014). Recent studies about dynamic optimization have reported significant performance improvements with economically-oriented NMPC formulations (Zavala and Biegler, 2009).

Wang et al. (2017) proposed a strategy to eliminate model mismatch between the dynamic RTO and the control layer. Elimination of model mismatch 
between D-RTO and the control layer ensures that problems such as unreachability and infeasibility of the trajectories calculated by D-RTO do not appear. The strategy transforms the dynamic model equations into a nonlinear algebraic model by using a trapezoidal formula. This nonlinear model is applied in both layers, but also the same discretization method and the same intervals are used.

In this context, the proposed approach was integrated with a dynamic optimization layer, without the necessity of an intermediate layer. In this way, the optimal path obtained in D-RTO is sent to the control layer, which will be responsible to take the plant through the optimal trajectory. The mathematical formulation of the dynamic optimization layer is illustrated in Equations 26 to 27.

$$
\left\{\mathrm{y}^{\mathrm{DR}}\left(\mathrm{t}_{\mathrm{k}}\right), \mathrm{u}^{\mathrm{DR}}\left(\mathrm{t}_{\mathrm{k}}\right)\right\}=\underset{\underline{\mathrm{y}}\left(\mathrm{t}_{\mathrm{k}}\right), \underline{\mathrm{u}}\left(\mathrm{t}_{\mathrm{k}}\right), \underline{\mathrm{d}}\left(\mathrm{t}_{\mathrm{k}}\right)}{\arg \min } \varphi\left(\mathrm{t}_{\mathrm{n}}\right)
$$

s.t.

$\mathrm{F}\left(\underline{\dot{x}}\left(\mathrm{t}_{\mathrm{k}}\right), \underline{\mathrm{x}}\left(\mathrm{t}_{\mathrm{k}}\right), \underline{\mathrm{y}}\left(\mathrm{t}_{\mathrm{k}}\right), \underline{\mathrm{u}}\left(\mathrm{t}_{\mathrm{k}}\right), \mathrm{p}, \mathrm{t}_{\mathrm{k}}\right)=0, \quad \mathrm{x}\left(\mathrm{t}_{0}\right)=\mathrm{x}_{0} ; \quad \mathrm{t}_{\mathrm{k}} \in\left[\mathrm{t}_{0}, \mathrm{t}_{\mathrm{n}}\right]$

$\underline{\mathrm{x}}^{\mathrm{L}} \leq \underline{\mathrm{x}}\left(\mathrm{t}_{\mathrm{k}}\right) \leq \underline{\mathrm{x}}^{\mathrm{U}}$

$\underline{y}^{\mathrm{L}} \leq \underline{\mathrm{y}}\left(\mathrm{t}_{\mathrm{k}}\right) \leq \underline{\mathrm{y}}^{\mathrm{U}}$

$\left.\underline{\mathrm{u}}^{\mathrm{L}} \leq \underline{\mathrm{u}}^{(\mathrm{t}} \mathrm{k}\right) \leq \underline{\mathrm{u}}^{\mathrm{U}}$

where $\phi(t)$ is the objective function, $F(\bullet) \in \mathfrak{R}^{\mathrm{n}_{\mathrm{x}}}+\mathrm{n}_{\mathrm{y}}$ is the differential algebraic equation system (DAE), $\underline{x}\left(t_{k}\right) \in \mathfrak{R}^{n_{x}}$ are the state variables, $\underline{y}\left(t_{k}\right) \in \mathfrak{R}^{n_{y}}$ are the controlled variables, $\underline{u}\left(t_{k}\right) \in \mathfrak{R}^{n_{u}}$ are the manipulated variables, and $p \in \mathfrak{R}^{n} p$ are the time independent parameters.

The differential-algebraic optimization problem (DAOP) illustrated by Equations 26 and 27 was reformulated as a multi-objective optimization problem using time-varying constraint relaxation techniques. Equations 28 and 29 show the mathematical formulation of the multi-objective optimization problem by relaxing the constraints with time-varying slack variables, $s(t)$ (Almeida and Secchi, 2012).

$$
\begin{aligned}
& \min _{\underline{\underline{u}}\left(\mathrm{t}_{\mathrm{k}}\right), \underline{\underline{x}}^{\mathrm{x}}\left(\mathrm{t}_{\mathrm{k}}\right), \underline{s}^{\mathrm{y}}\left(\mathrm{t}_{\mathrm{k}}\right), \underline{s}^{\mathrm{u}}\left(\mathrm{t}_{\mathrm{k}}\right)}\left[\varphi\left(\mathrm{t}_{\mathrm{n}}\right), \int_{\mathrm{t}_{0}}^{\mathrm{t}_{\mathrm{f}}}\left(\underline{\mathrm{s}}^{\mathrm{x}}(\mathrm{t})\right)^{2} \mathrm{dt}, \int_{\mathrm{t}_{0}}^{\mathrm{t}_{\mathrm{f}}}\left(\underline{\mathrm{s}}^{\mathrm{y}}(\mathrm{t})\right)^{2} \mathrm{dt}, \int_{\mathrm{t}_{0}}^{\mathrm{t}_{\mathrm{t}}}\left(\underline{s}^{\mathrm{u}}(\mathrm{t})\right)^{2} \mathrm{dt},\right] \\
& \mathrm{F}\left(\underline{\dot{x}}\left(\mathrm{t}_{\mathrm{k}}\right), \underline{\mathrm{x}}\left(\mathrm{t}_{\mathrm{k}}\right), \underline{\mathrm{y}}\left(\mathrm{t}_{\mathrm{k}}\right), \underline{\mathrm{u}}\left(\mathrm{t}_{\mathrm{k}}\right), p, \mathrm{t}_{\mathrm{k}}\right)=0, \quad \mathrm{x}\left(\mathrm{t}_{0}\right)=\mathrm{x}_{0} ; \mathrm{t}_{\mathrm{k}} \in\left[\mathrm{t}_{0}, \mathrm{t}_{\mathrm{n}}\right] \\
& \underline{\mathrm{x}}^{\mathrm{L}} \leq \underline{\mathrm{x}}\left(\mathrm{t}_{\mathrm{k}}\right)+\underline{\mathrm{s}}^{\mathrm{x}}\left(\mathrm{t}_{\mathrm{k}}\right) \leq \underline{\mathrm{x}}^{\mathrm{U}} \\
& \underline{\mathrm{y}}^{\mathrm{L}} \leq \underline{\mathrm{y}}\left(\mathrm{t}_{\mathrm{k}}\right)+\underline{\mathrm{s}}^{\mathrm{y}}\left(\mathrm{t}_{\mathrm{k}}\right) \leq \underline{\mathrm{y}}^{\mathrm{U}}
\end{aligned}
$$

$$
\begin{aligned}
& \underline{\mathrm{u}}^{\mathrm{L}} \leq \underline{\mathrm{u}}^{\mathrm{u}}\left(\mathrm{t}_{\mathrm{k}}\right)+\underline{\mathrm{s}}^{\mathrm{u}}\left(\mathrm{t}_{\mathrm{k}}\right) \leq \underline{\mathrm{u}}^{\mathrm{U}} \\
& \underline{\mathrm{s}}_{\mathrm{L}}^{\mathrm{x}} \leq \underline{\mathrm{s}}^{\mathrm{x}}\left(\mathrm{t}_{\mathrm{k}}\right) \leq \underline{\mathrm{s}}_{\mathrm{U}}^{\mathrm{x}} \text { where } \underline{\mathrm{s}}^{\mathrm{x}}\left(\mathrm{t}_{\mathrm{k}}\right) \in \mathfrak{R}^{\mathrm{n}_{\mathrm{x}}} \\
& \underline{\mathrm{s}}_{\mathrm{L}}^{\mathrm{y}} \leq \underline{\mathrm{s}}^{\mathrm{y}}\left(\mathrm{t}_{\mathrm{k}}\right) \leq \underline{\mathrm{s}}_{\mathrm{U}}^{\mathrm{y}} \text { where } \underline{\mathrm{s}}^{\mathrm{y}}\left(\mathrm{t}_{\mathrm{k}}\right) \in \mathfrak{R}^{\mathrm{n}_{\mathrm{y}}} \\
& \underline{\mathrm{s}}_{\mathrm{L}}^{\mathrm{u}} \leq \underline{\mathrm{s}}^{\mathrm{u}}\left(\mathrm{t}_{\mathrm{k}}\right) \leq \underline{\mathrm{s}}_{U}^{\mathrm{u}} \text { where } \underline{\underline{s}}^{\mathrm{u}}\left(\mathrm{t}_{\mathrm{k}}\right) \in \mathfrak{R}^{\mathrm{n}_{\mathrm{u}}}
\end{aligned}
$$

where $s^{x}(\mathrm{tk})$ are time-varying slacks by relaxing to constraints of state variables, $s^{y}(\mathrm{tk})$ are time-varying slacks by relaxing to constraints of controlled variables and $s^{u}(\mathrm{tk})$ are time-varying slacks by relaxing to constraints of manipulated variables. The proposed approach allows direct integration between the dynamic optimization layer and control layer, Equation 30.

$\underline{y}^{S P}\left(t_{k}\right)=\underline{y}^{D R}\left(t_{k}\right), \quad t_{k} \in\left[t_{0}, t_{n}\right]$

The ability of the proposed model to describe plant behavior allows one to insert a contribution in the objective function of the control layer that represents the economical performance of the process, avoiding the necessity of an optimization layer. In this way, the economic optimization will be solved at the same frequency as the control problem. Therefore, the proposed model is promising for use in economic model predictive control strategies, EMPC.

\section{RESULTS AND DISCUSSION}

The benchmark CSTR (controlled stirred tank reactor) of Van de Vusse was chosen as the case study because of its well-known nonlinear behavior. The system is represented by the synthesis of cyclopentenol (component B) from cyclopentadiene (component A) by addition of acid water catalyst. Due to the strong reactivity of the reactants and products, dicyclopentadiene (component $\mathrm{D}$ ) is produced as a secondary product of the Diels-Alder reaction, and cyclopentenodiol (component $\mathrm{C}$ ) is produced by the consecutive addition of another water molecule (Klatt and Engell, 1998). The equations that describe the chemical reactions of the process are the following:

$$
\begin{aligned}
& \mathrm{C}_{5} \mathrm{H}_{6} \stackrel{\mathrm{H}_{2} \mathrm{O} / \mathrm{H}^{+}}{\longrightarrow} \mathrm{C}_{5} \mathrm{H}_{7} \mathrm{OH} \stackrel{\mathrm{H}_{2} \mathrm{O} / \mathrm{H}^{+}}{\longrightarrow} \mathrm{C}_{5} \mathrm{H}_{8}(\mathrm{OH})_{2} \\
& 2 \mathrm{C}_{5} \mathrm{H}_{6} \rightarrow \mathrm{C}_{10} \mathrm{H}_{12}
\end{aligned}
$$

The mass and energy balances in the CSTR (continuous stirred tank reactor), with constant volume, and control system as shown in Figure 1, result in the following equations: 


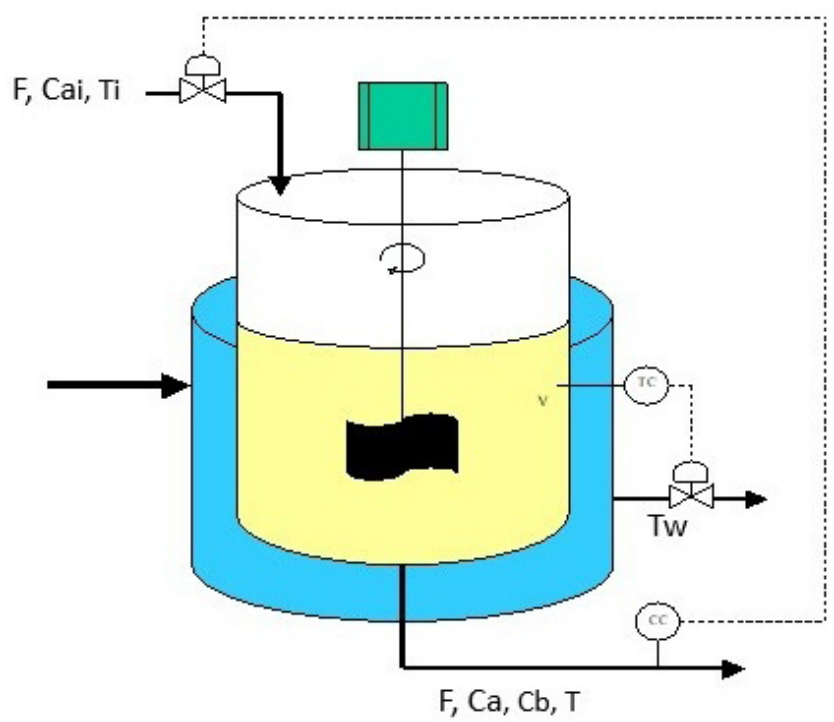

Figure 1. The schematic of the reactor of Van de Vusse.

$$
\begin{aligned}
& \frac{d_{a}}{d t}=\frac{F}{V}\left(C_{a_{i n}}-C_{a}\right)-K_{1}(T) C_{a}-K_{3}(T) C_{a}^{2} \\
& \frac{d C_{b}}{d t}=\frac{F}{V} C_{b}+K_{1}(T) C_{a}-K_{2}(T) C_{b} \\
& \frac{d T}{d t}=-\frac{1}{\rho C_{P}}\left[K_{1}(T) C_{a}\left(-\Delta H_{R_{A B}}\right)+K_{2}(T) C_{b}\left(-\Delta H_{R_{B C}}\right)+K_{3}(T) C_{a}^{2}\left(-\Delta H_{R_{A D}}\right)\right]+ \\
& \frac{F}{V}\left(T_{i n}-T\right)+\frac{K_{w} A_{R}}{\rho C_{P} V}\left(T_{w}-T\right) \\
& K_{i}(T)=K_{i 0} \exp \left(-\frac{E_{i}}{R T}\right)
\end{aligned}
$$

where $C_{a}$ and $C_{b}$ are the molar concentrations of species $\mathrm{A}$ and $\mathrm{B}$, respectively, $C_{\text {ain }}$ is the inlet concentration of species A, $T$ is the reactor temperature, $T_{w}$ is the jacket temperature, $T_{\text {in }}$ is the inlet temperature, $F$ is the feed flow rate, $V$ is the reactor volume, $A R$ is the heat transfer area, $K_{w}$ is the overall heat transfer coefficient. Table 1 shows the model parameters.

Figure 2 illustrates the nonlinear steady-state behavior of the composition $C_{b}$ as function of the manipulated variables, $F$ and $T_{w}$, of the Van de Vusse reactor. This case study is suitable to verify the controller performance, because there is nonlinearity of the controlled variable $C_{b}$ with both manipulated variables, $F$ and $T_{w}$. For instance, if we choose any curve in the figure, where $T_{w}$ is constant, there is an inversion of the gain signal of the $C_{b}$ composition with the feed flow rate. On the other hand, if we draw and walk up in a vertical line, where the feed flow rate is constant and close to the lower bound of the feed flow rate, the reaction rate increases when $\mathrm{T}_{\mathrm{w}}$ is reduced, maximizing the $C_{b}$ production. However, when we are on the other side, close to the upper bound of the feed flow rate, the reaction rate increases when $T_{w}$ is

Table 1. CSTR parameters for the case study (Trierweiler, 1997).

\begin{tabular}{ccc}
\hline Parameters & Value & Unit \\
\hline $\mathrm{K}_{10}$ & $1.287 \times 10^{12}$ & $\mathrm{~h}^{-1}$ \\
$\mathrm{~K}_{20}$ & $1.287 \times 10^{12}$ & $\mathrm{~h}^{-1}$ \\
$\mathrm{~K}_{30}$ & $9.043 \times 10^{9}$ & $\mathrm{~L} /(\mathrm{mol} \mathrm{A} \cdot \mathrm{h})$ \\
$\left(-\mathrm{E}_{1} / \mathrm{R}\right)$ & 9758.3 & $\mathrm{~K}$ \\
$\left(-\mathrm{E}_{2} / \mathrm{R}\right)$ & 9758.3 & $\mathrm{~K}$ \\
$\left(-\mathrm{E}_{3} / \mathrm{R}\right)$ & 8560.0 & $\mathrm{~K}$ \\
$\left(-\Delta \mathrm{H}_{\mathrm{RAB}}\right)$ & -4.20 & $\mathrm{~kJ} /(\mathrm{mol} \mathrm{A})$ \\
$\left(-\Delta \mathrm{H}_{\mathrm{RAC}}\right)$ & 11.0 & $\mathrm{~kJ} /(\mathrm{mol} \mathrm{B})$ \\
$\left(-\Delta \mathrm{H}_{\mathrm{RAD}}\right)$ & 41.85 & $\mathrm{~kJ} /(\mathrm{mol} \mathrm{A})$ \\
$\dot{\rho}_{\mathrm{C}}$ & 0.9342 & $\mathrm{~kg} / \mathrm{L}$ \\
$\mathrm{K}_{\mathrm{W}}$ & 3.01 & $\mathrm{~kJ} /(\mathrm{kg} \cdot \mathrm{K})$ \\
$\mathrm{A}_{\mathrm{R}}$ & 4032.0 & $\mathrm{~kJ} /\left(\mathrm{h} \cdot \mathrm{K} \cdot \mathrm{m}^{2}\right)$ \\
$\mathrm{V}$ & 0.215 & $\mathrm{~m}$ \\
\end{tabular}

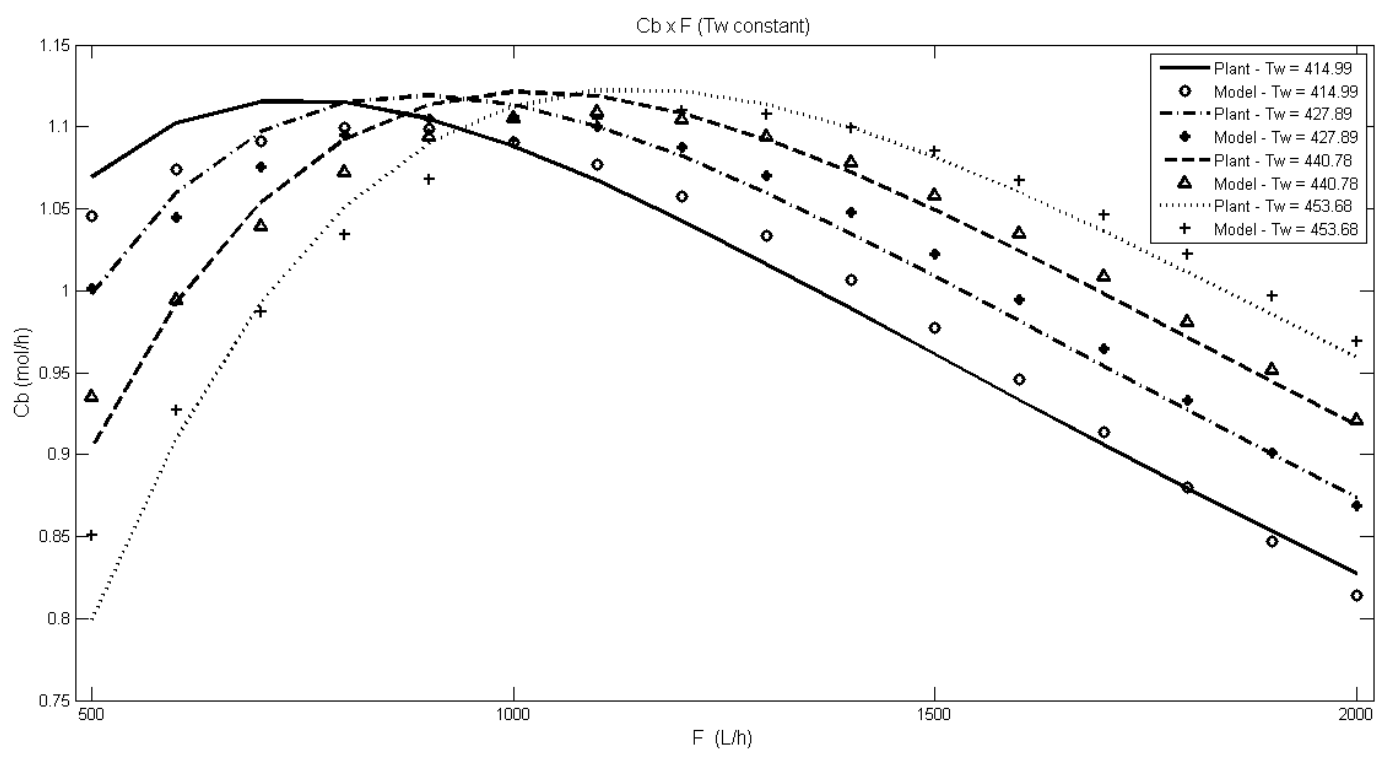

Figure 2. Steady state of $C_{b}$ composition. 
increased. Therefore, there is also an inversion of the gain signal in the relationship between the variables $T_{w}$ and $C_{b}$. Besides that, the results are important because they show that the multi-parametric model can describe the steady-sate region very well.

\section{Process Identification}

The NMPC was configured with two manipulated variables, $F$ and $T_{w}$, two controlled variables, $C_{b}$ and $T$, and two disturbance variables, $C_{\text {ain }}$ and $T$. Equations 6 to 9 are a representation of Equations 37 to 40 used to describe the behavior of the Van de Vusse reactor in the MPC algorithm. Tables 2 and 3 show the parameters obtained from the identification procedure.

$$
\begin{aligned}
& y_{j}(t)=y_{j}^{0}+\left[\underline{y_{j}^{0}}-\underline{y_{j}^{s s}}\left(F, T_{w}, C_{a i n}, T_{i n}\right)\right] f_{j}(t) \\
& \mathrm{f}_{\mathrm{j}}(\mathrm{t})=1-\exp \left[\frac{-\varepsilon_{\mathrm{j}}\left(\mathrm{t}-\tau_{\mathrm{d}_{\mathrm{j}}}\right)}{\tau_{\mathrm{d}_{\mathrm{j}}}}\right]\left\{\cosh \left[\frac{\sqrt{\varepsilon_{\mathrm{j}}^{2}-1}}{\tau_{\mathrm{j}}}\left(\mathrm{t}-\tau_{\mathrm{d}_{\mathrm{j}}}\right)\right]+\right. \\
& \left.\frac{\varepsilon_{\mathrm{j}}}{\sqrt{\varepsilon_{\mathrm{j}}^{2}-1}} \sinh \left[\frac{\sqrt{\varepsilon_{\mathrm{j}}^{2}-1}}{\tau_{\mathrm{j}}}\left(\mathrm{t}-\tau_{\mathrm{d}_{\mathrm{j}}}\right)\right]\right\} \\
& \mathrm{y}_{\mathrm{j}}^{\mathrm{ss}}=\left[\mathrm{C}_{\mathrm{b}}^{\mathrm{ss}}, \mathrm{T}^{\mathrm{ss}}\right] \quad \text { and } \quad \mathrm{y}_{\mathrm{j}}(\mathrm{t})=\left[\mathrm{C}_{\mathrm{b}}(\mathrm{t}), \mathrm{T}(\mathrm{t})\right] \\
& \mathrm{y}_{\mathrm{j}}^{\mathrm{ss}}\left(\mathrm{F}, \mathrm{T}_{\mathrm{w}}, \mathrm{C}_{\text {ain }}, \mathrm{T}_{\mathrm{in}}\right)=\mathrm{C}_{\mathrm{j}, 1}+\mathrm{C}_{\mathrm{j}, 2}\left(\mathrm{C}_{\text {ain }}, \mathrm{T}_{\mathrm{in}}\right) \mathrm{F}+\mathrm{C}_{\mathrm{j}, 3}\left(\mathrm{C}_{\text {ain }}, \mathrm{T}_{\mathrm{in}}\right) \mathrm{T}_{\mathrm{w}}+\mathrm{C}_{\mathrm{j}, 4}\left(\mathrm{C}_{\text {ain }}, \mathrm{T}_{\text {in }}\right) \mathrm{FT}_{\mathrm{w}}+ \\
& \mathrm{C}_{\mathrm{j}, 5}\left(\mathrm{C}_{\text {ain }}, \mathrm{T}_{\text {in }}\right) \mathrm{F}^{2}+\mathrm{C}_{\mathrm{j}, 6}\left(\mathrm{C}_{\text {ain }}, \mathrm{T}_{\text {in }}\right) \mathrm{T}_{\mathrm{w}}^{2} \\
& \mathrm{C}_{\mathrm{j}, 1}\left(\mathrm{C}_{\mathrm{ain}}, \mathrm{T}_{\mathrm{in}}\right)=\mathrm{k}_{\mathrm{j}, 1,1}+\mathrm{k}_{\mathrm{j}, 1,2} \mathrm{C}_{\mathrm{ain}}+\mathrm{k}_{\mathrm{j}, 1,3} \mathrm{~T}_{\mathrm{in}}+\mathrm{k}_{\mathrm{j}, 1,4} \mathrm{C}_{\mathrm{ain}} \mathrm{T}_{\mathrm{in}}+\mathrm{k}_{\mathrm{j}, 1,5} \mathrm{C}_{\mathrm{ain}}^{2}+\mathrm{k}_{\mathrm{j}, 1,6} \mathrm{~T}_{\mathrm{in}}^{2}
\end{aligned}
$$

Figures 3 to 6 illustrate a comparison between the proposed model and the plant for the steady and dynamic behaviors of the controlled variables, $C_{b}$ and $T$, for step changes in the manipulated variables, $F$ and

Table 2. Parameters of the steady-state model.

\begin{tabular}{ccccccc}
\hline $\mathbf{C}_{\mathbf{j}, \mathbf{1}}$ & $\mathbf{K}_{\mathbf{j}, 1,1}$ & $\mathbf{K}_{\mathbf{j}, \mathbf{1}, \mathbf{2}}$ & $\mathbf{K}_{\mathbf{j}, \mathbf{1 , 3}}$ & $\mathbf{K}_{\mathbf{i}, 1,4}$ & $\mathbf{K}_{\mathbf{j}, \mathbf{1}, 5}$ & $\mathbf{K}_{\mathbf{j}, 1,6}$ \\
\hline $\mathrm{C}_{1,1}$ & 0.3236 & 0.1525 & 0.3805 & -0.049 & 0.0028 & -0.359 \\
$\mathrm{C}_{1,2}$ & -1.077 & -0.599 & -0.182 & 2.9490 & 0.1381 & 7.8941 \\
$\mathrm{C}_{1,3}$ & 0.5271 & 0.4653 & 1.6030 & 5.7304 & 0.3474 & 10.922 \\
$\mathrm{C}_{1,4}$ & 2.5515 & 1.0075 & -1.599 & -11.35 & -0.654 & -22.91 \\
$\mathrm{C}_{1,5}$ & 0.7214 & 0.590 & 1.0970 & -4.665 & -0.143 & -12.54 \\
$\mathrm{C}_{1,6}$ & 1.9308 & 0.977 & -1.185 & -15.01 & -0.885 & -36.81 \\
$\mathrm{C}_{2,1}$ & 90.595 & 1.509 & 33.818 & 1.6809 & 0.4415 & 2.4816 \\
$\mathrm{C}_{2,2}$ & 18.698 & -2.42 & 37.410 & 15.276 & 0.3364 & 11.631 \\
$\mathrm{C}_{2,3}$ & 77.542 & 4.388 & 6.6873 & 24.790 & 2.8896 & 4.6919 \\
$\mathrm{C}_{2,4}$ & -116.3 & 5.245 & -6.556 & -36.78 & -0.991 & 9.9687 \\
$\mathrm{C}_{2,5}$ & -6.956 & -0.70 & -54.04 & -22.61 & -1.303 & -11.32 \\
$\mathrm{C}_{2,6}$ & 4.6948 & 5.214 & -4.864 & -68.70 & -3.957 & -62.69 \\
\hline
\end{tabular}

Table 3. Parameters of the dynamic model.

\begin{tabular}{cccc}
\hline Parameters & $\boldsymbol{\varepsilon}_{\mathbf{j}}$ & $\boldsymbol{\tau}_{\mathbf{j}}$ & $\boldsymbol{\tau}_{\mathbf{d j}}$ \\
\hline $\mathrm{f}_{1}(\mathrm{t})$ & 1.887 & 0.1905 & 0.00234 \\
$\mathrm{f}_{2}(\mathrm{t})$ & 2.903 & 0.8050 & $1.1 \times 10^{-5}$ \\
\hline
\end{tabular}

$T_{w}$, and in the disturbance variables, $C_{\text {ain }}$ and $T_{a i n}$. The results show that the models for $C_{b}(t)$ and $T(t)$ describe well the plant behavior in all regions, allowing the use in NMPC and optimization strategies.

\section{Application of the proposed NMPC in the case study}

The formulation of the NMPC presented in Equation 1 was employed with $y^{S P}\left(t_{k}\right)=\left[C_{b}^{S P}\left(t_{k}\right), T^{S P}\left(t_{k}\right)\right], y\left(t_{k}\right)=$ $\left[C_{b}\left(t_{k}\right), T\left(t_{k}\right)\right]$ and $u\left(t_{k}\right)=\left[F\left(t_{k}\right), T_{w}\left(t_{k}\right)\right]$, where the tuning parameters are $\Delta u\left(t_{k}\right)=\left[\Delta F\left(t_{k}\right), \Delta T_{w}\left(t_{k}\right)\right]=[100 \mathrm{~L} / \mathrm{h}$, $10 K], W_{v}\left(t_{k}\right)=\left[W_{C_{b}}\left(t_{k}\right), W_{T}\left(t_{k}\right)\right]=[100,10],\left[R_{\Delta F}\left(T_{k}\right)\right.$, $\left.R_{\Delta T_{w}}\left(T_{k}\right)\right]=[10,10], R_{u}\left(t_{k}\right)=\left[R_{F}\left(t_{k}\right), R_{T_{w}}\left(t_{k}\right)\right]=[1,1]$, $t_{\text {sampling }}=5 \mathrm{~min}, H_{P}=50,{ }_{H C}=10$.

The objective of this study was to evaluate the NMPC performance using the proposed model in comparison with the NMPC using the rigorous model to follow the suggested setpoints for $C_{b}$ and $T$. Furthermore, the capability of the proposed NMPC to reject disturbances was tested.

Figures 7 to 8 illustrate the good performance of the proposed controller to lead the plant smoothly to the setpoints. Both figures show a small bias in temperature at the first moment, before the $C_{b}$ setpoint changed. It happened because, at this moment, the feed flow rate was at the minimum limit, leaving the controller with only one degree of freedom and two foci, since the $C_{b}$ setpoint is more important than Temperature. The code was written in Matlab platform and the Interior Point algorithm (Byrd et al., 1999) was chosen to solve the nonlinear problem. The algorithm did not spend a lot of computational time, approximately 0.66 seconds per cycle in a machine with 8GB RAM and an i7 processor, to solve the NLP problem with 2 manipulated variables, 2 controlled variables and 2 disturbance variables.

Figures 9 and 10 show the good performance of the proposed controller also to reject disturbances in the feed, $C_{a i n}$ and $T_{\text {ain }}$, keeping the controlled variables, $C_{b}$ and $T$, at the setpoints. Similarly to previous results, there is a bias to the temperature caused by the loss of one degree of freedom when the feed flow rate hit the lower bound, leaving the controller with just one manipulated variable to control two controlled variables.

Figures 11 and 12 shows the performance of the proposed NMPC and the QDMC (Garcia and Morshedi, 1986) using the linear model obtained in the first step of the identification procedure. The results with the NMPC show offsets in two setpoint changes. In the first, both manipulated variables are at the lower bounds. In the second, there is an offset only in the $C_{b}$ composition, because the jacket temperature is at the upper bound and the controller has only one manipulated variable to control two controlled variables. Therefore, in all situations the proposed NMPC did the best that it can do with the chosen boundary constraints. The results 

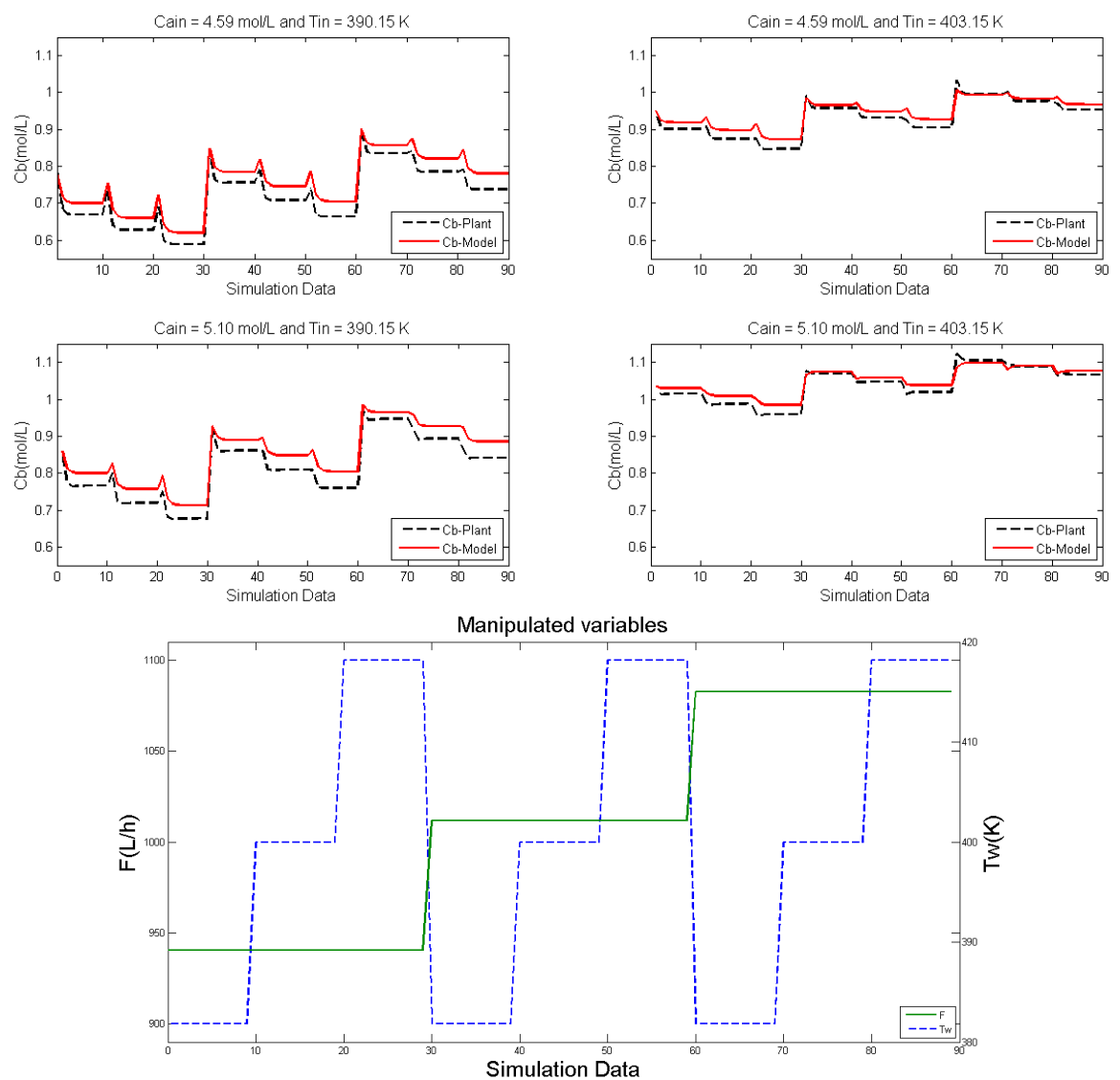

Figure 3. Identification of the dynamic model for $C_{b}$.
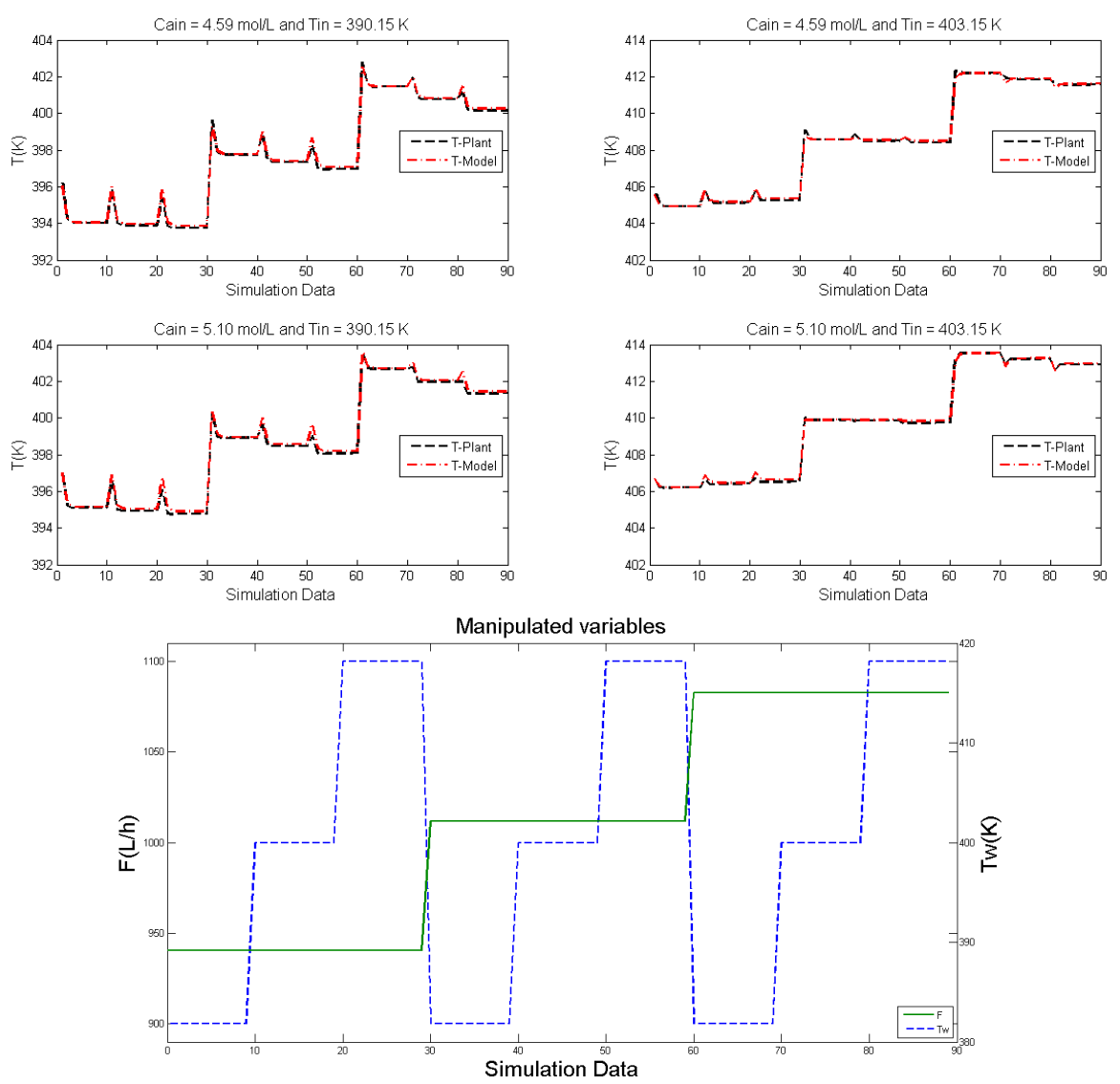

Figure 4. Identification of the dynamic model for temperature 

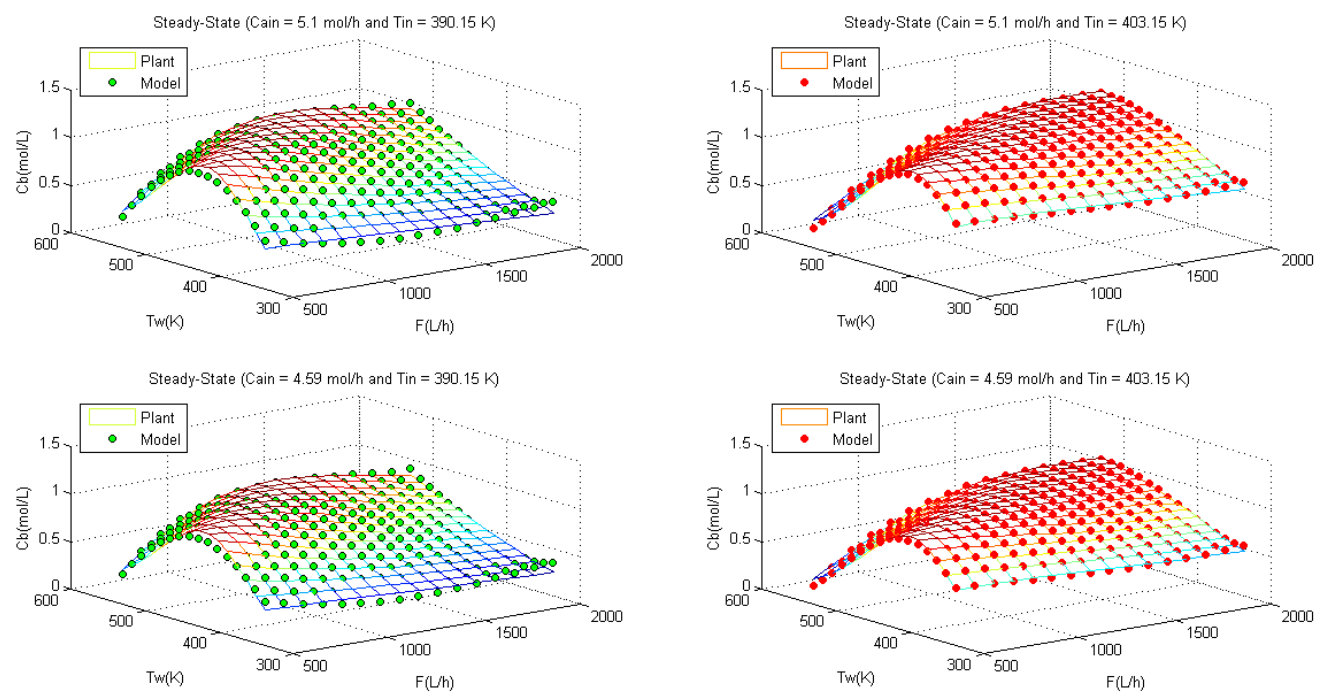

Figure 5. Identification of the steady-state model for $C_{b}$.
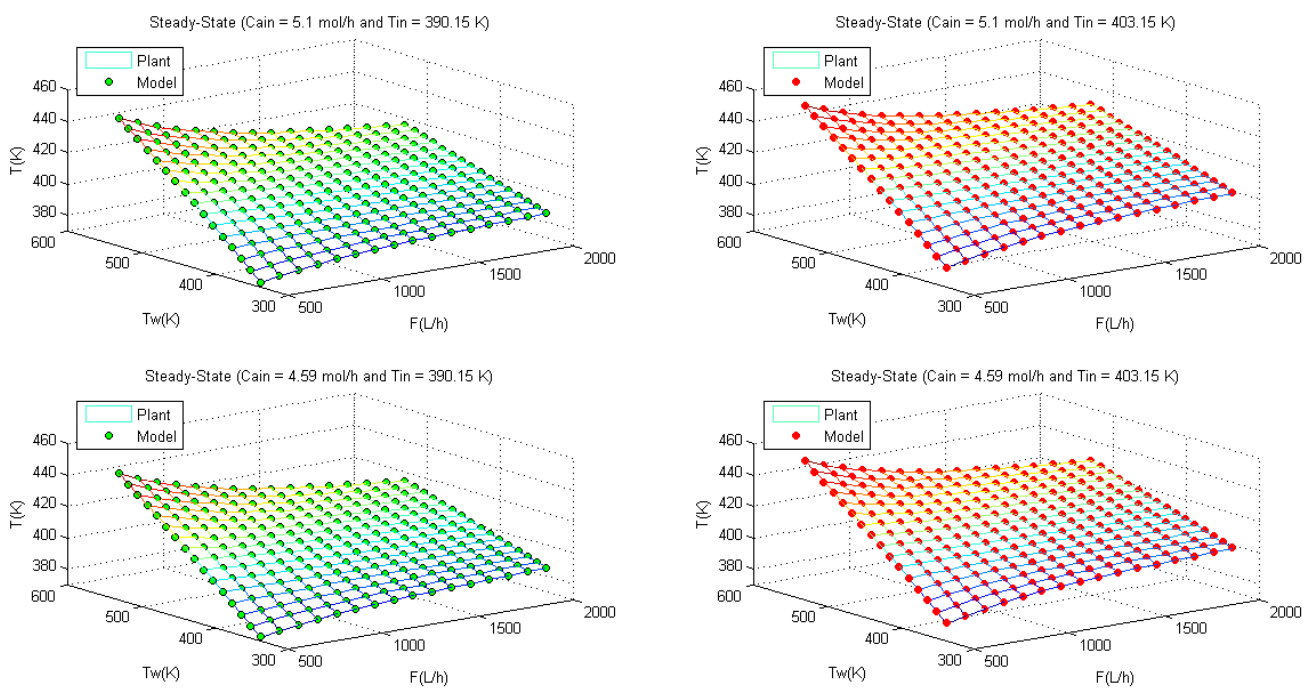

Figure 6. Identification of the steady-state model for temperature.
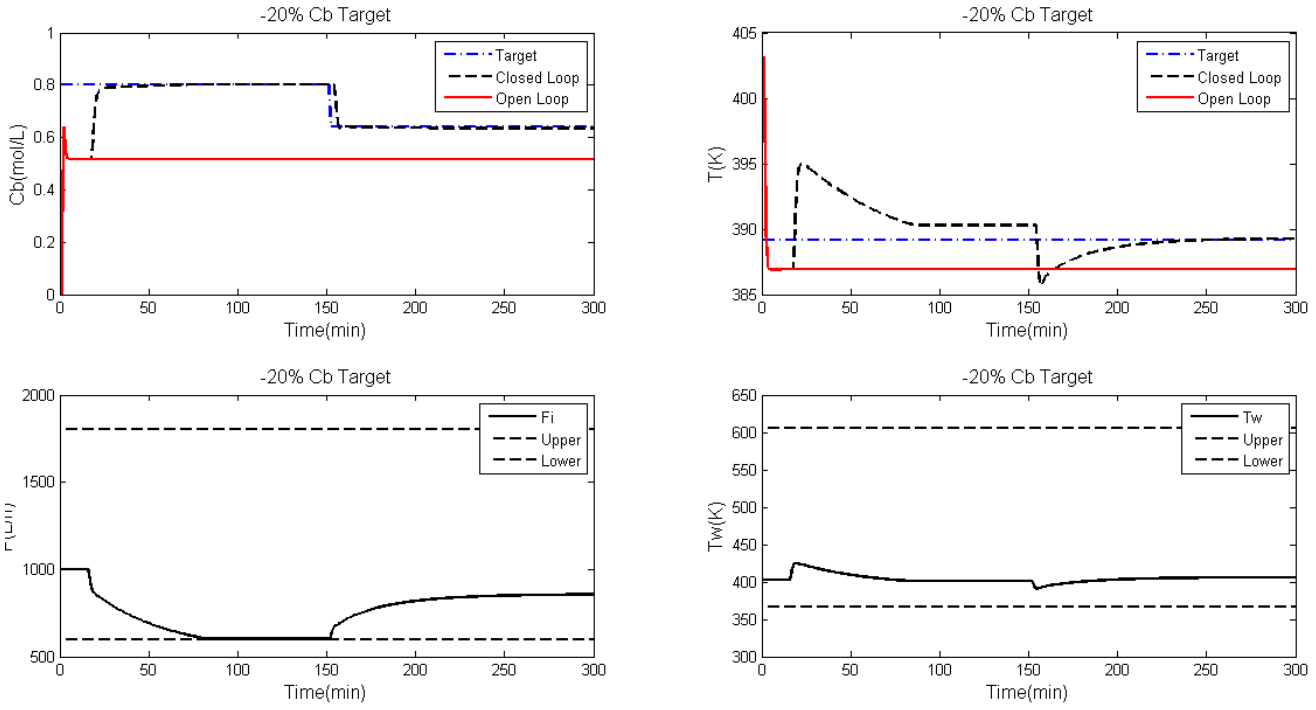

Figure 7. Result of the proposed NMPC to keep the plant on the $C_{b}$ setpoint. The controller turned on at time equal to $15 \mathrm{~min}$ and the $C_{b}$ setpoint changed at time equal to $150 \mathrm{~min}$. 

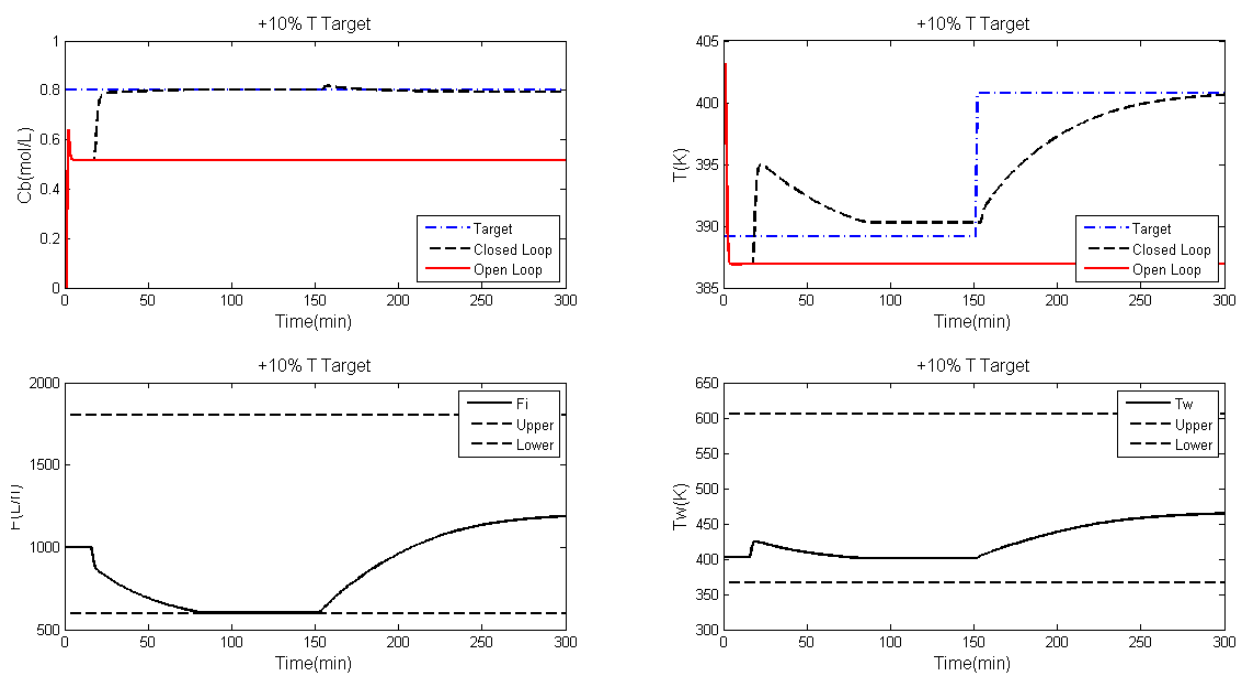

Figure 8. Result of the proposed NMPC to keep the plant on the temperature setpoint. The controller turned on at time equal to $15 \mathrm{~min}$ and the setpoint changed at time equal to $150 \mathrm{~min}$.
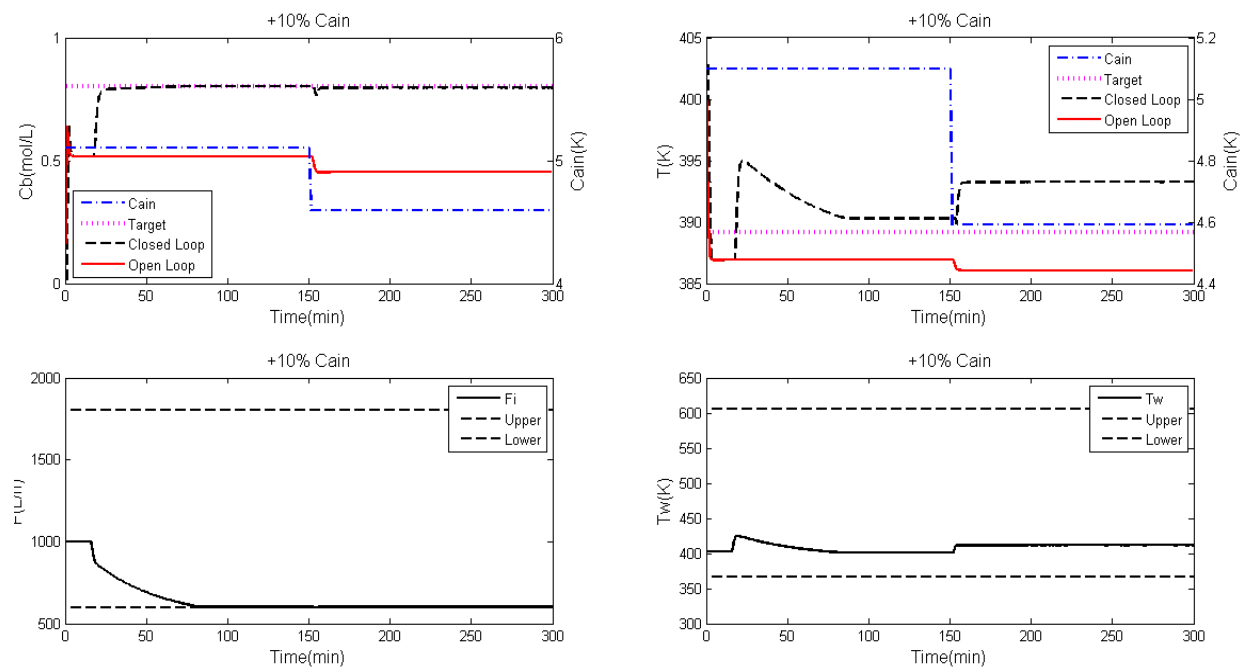

Figure 9. Result of the proposed NMPC to reject disturbances in the feed composition; The controller turned on at time equal to $15 \mathrm{~min}$ and the disturbance happened at time equal to $150 \mathrm{~min}$.
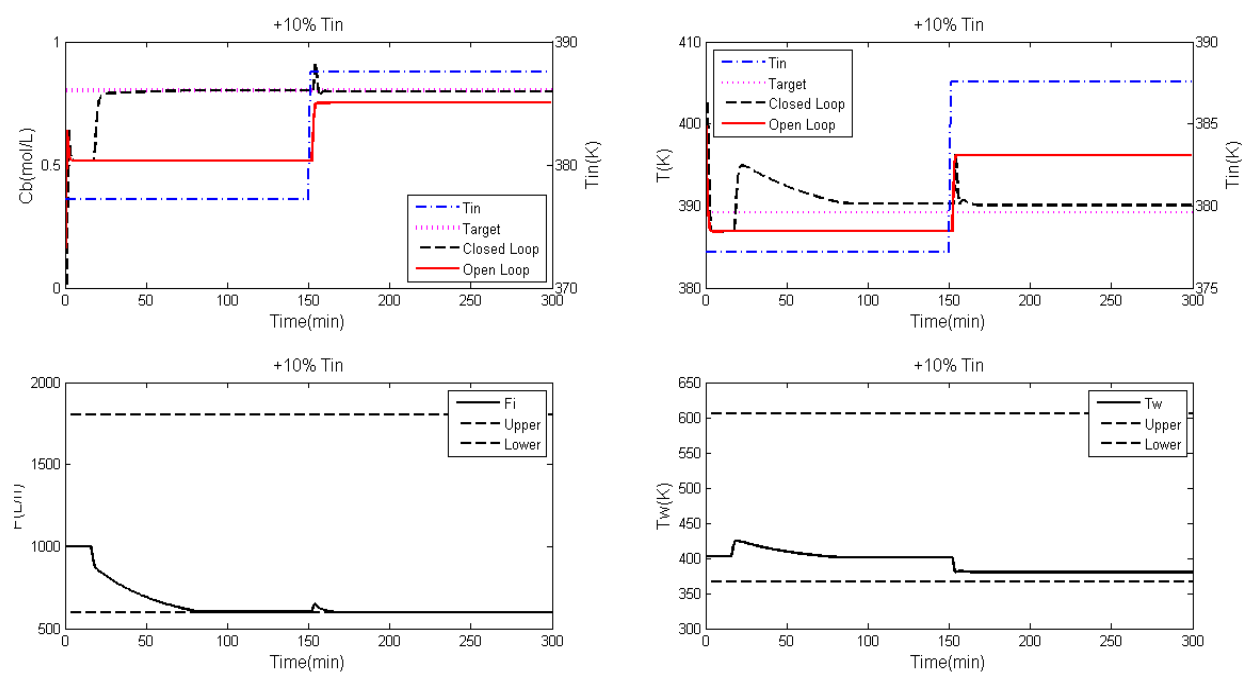

Figure 10. Result of the proposed NMPC to reject disturbances in the feed temperature. The controller turned on at time equal to $15 \mathrm{~min}$ and the disturbance happened at time equal to $150 \mathrm{~min}$. 

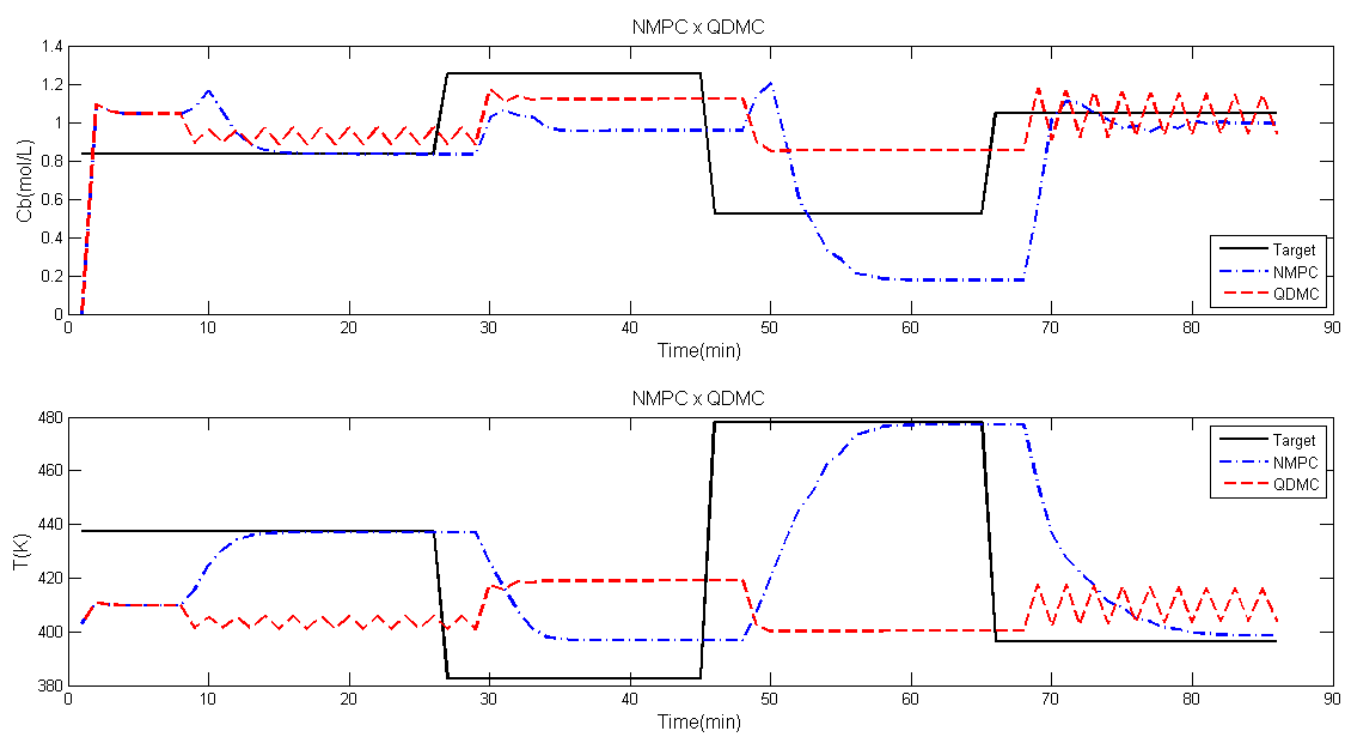

Figure 11. Comparison between the controlled variables obtained from the proposed NMPC and the traditional QDMC.
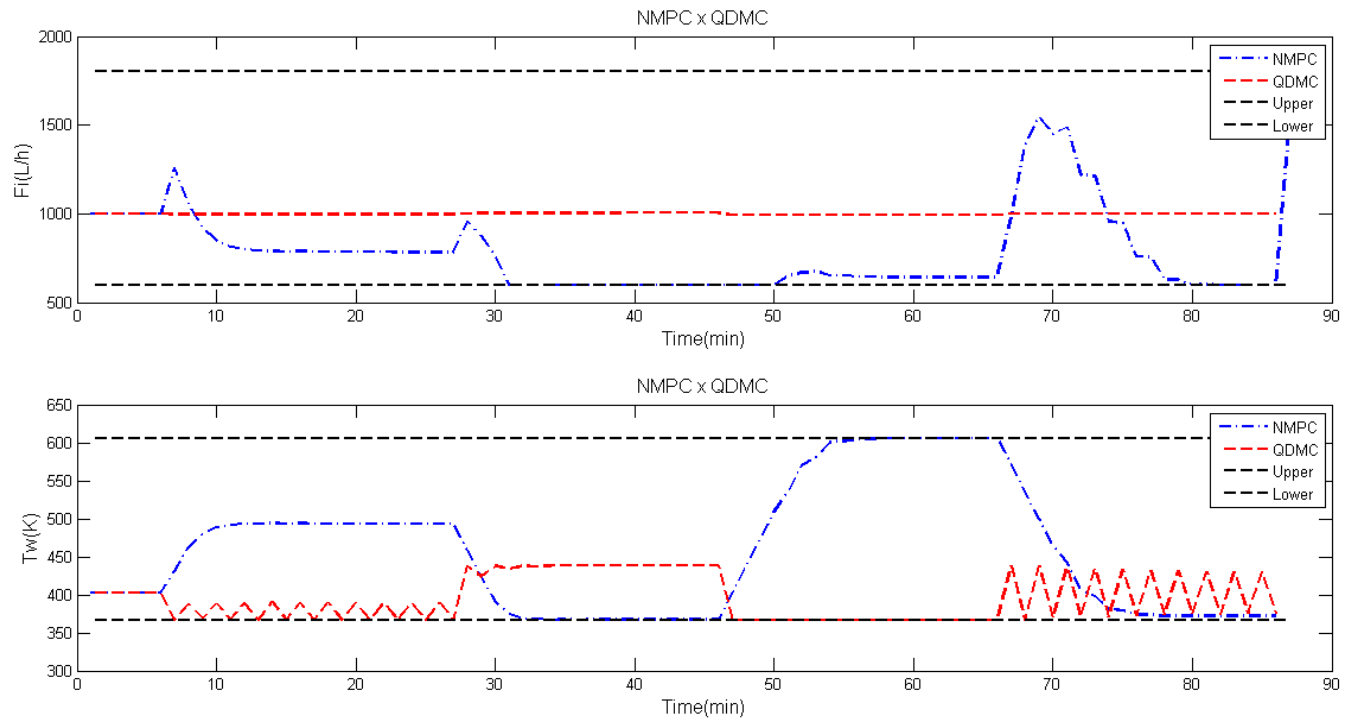

Figure 12. Comparison between the manipulated variables obtained from the proposed NMPC and the traditional QDMC.

obtained with the QDMC algorithm were oscillatory, showing the difficulty to represent the process behavior with linear models.

Figures 13 and 14 illustrate a comparison between the NMPC algorithm using rigorous models with the proposed NMPC. There are offsets in three situations. In the first, the $C_{b}$ target is unreachable with the $F_{i}$ limits used in the control problem, as we can see in Figure 2. In the second, when the targets change again, there is an offset just of the $C_{b}$ composition. This happens because, in this condition, the controller has only one manipulated variable, $F$, which is at the lower limit, to control two controlled variables. In the last suggested targets, both manipulated variables hit the lower limits, leaving an offset between plant and target for both controlled variables. Therefore, in all situations the proposed NMPC did the best that is possible to do with the chosen limits to manipulation. The results show that there is no performance loss when the controller uses the proposed model. However, the proposed NMPC reduced significantly the computational time to solve the NLP problem. In other words, the time spent in each cycle using the NMPC with the proposed model was approximately 15 times shorter than the algorithm using the rigorous model. This is a very important result, showing the potential of the algorithm to solve large-scale problems.

Comparison between the NMPC control using the proposed model and the Adaptive MPC algorithm

Figure 15 illustrates a comparison between the NMPC algorithm using the proposed model to solve 

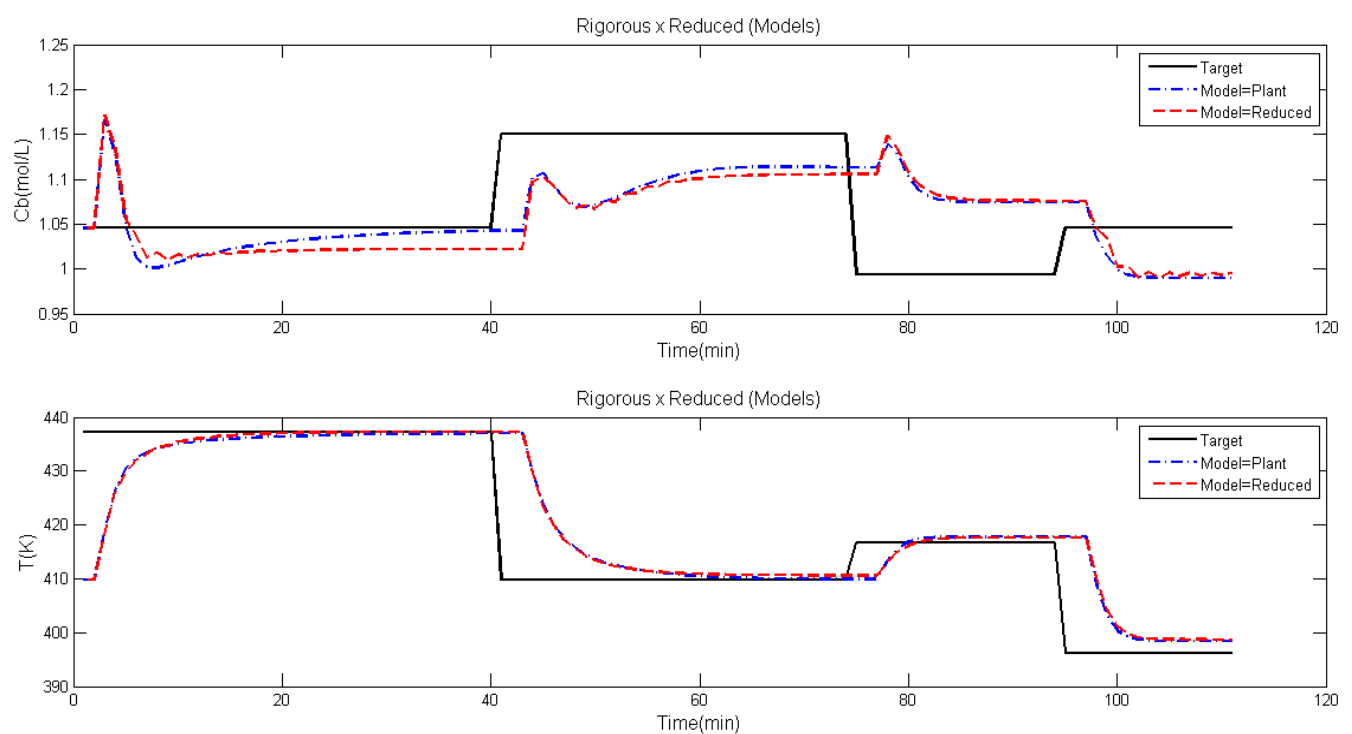

Figure 13. Comparison between the controlled variables obtained from the NMPC algorithm using the proposed model and the rigorous model.
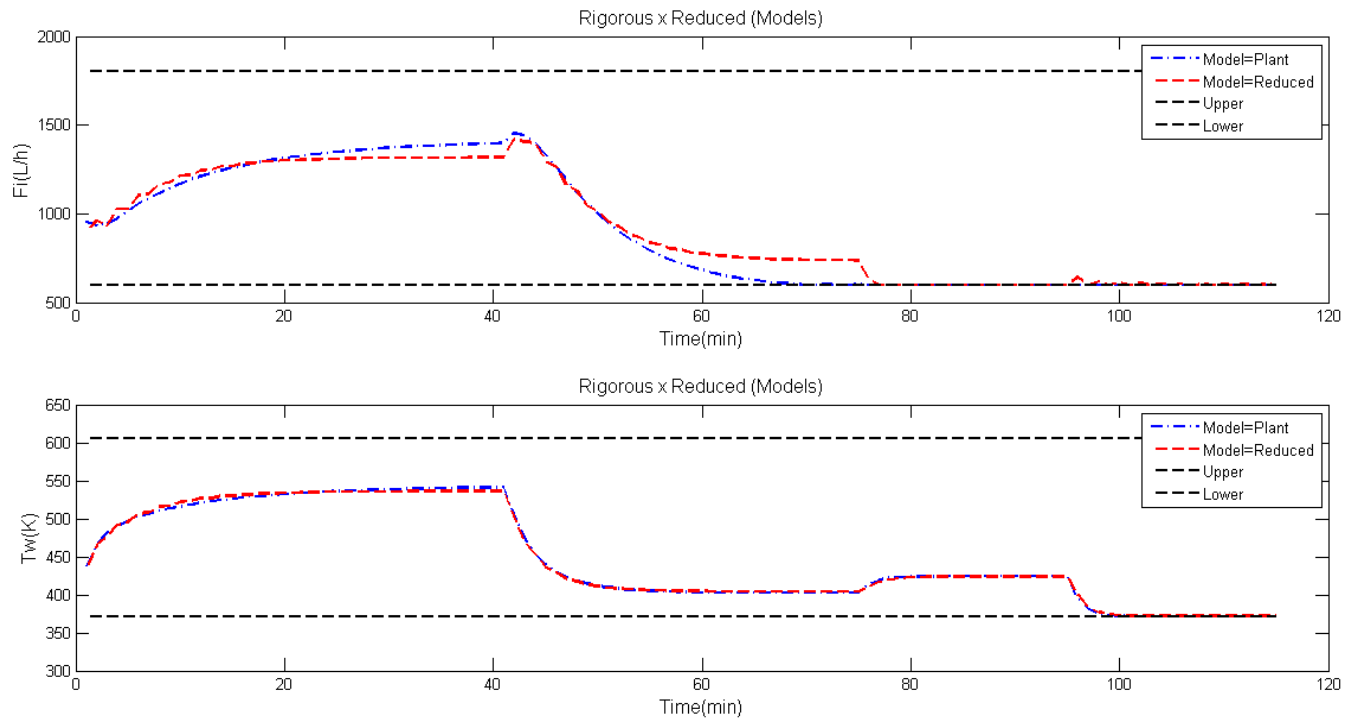

Figure 14. Comparison between the manipulated variables obtained from the NMPC algorithm using the proposed model and the rigorous model.

the NLP problem and the adaptive MPC strategy. In the adaptive MPC, the static gain is updated at the beginning of each cycle of the controller using the nonlinear function that represents the steady-state in the proposed model. The main difference between the approaches is that, in the NMPC algorithm, the steady-state is considered to be nonlinear during the solution of the control problem, resulting in a NLP problem, while in the adaptive approach, the nonlinear behavior is described for an adaptive linear model that is updated with the current condition read from the plant at the beginning of each control cycle. In other words, the linear model assumes an adaptive feature because the approach changes the steady-state gain according to the operating condition of the plant, being able to describe an inverse gain signal, for instance.
The adaptive MPC disadvantage is that the model is not updated along the prediction trajectory, staying the same during the solution of the control problem. The results show that both approaches spent similar computational time to solve the control problem, but the NMPC with the proposed analytical model had a better performance than adaptive MPC to keep the controlled variable at the setpoints.

\section{Sensitivity analysis of error in parameters of the NMPC reduced model}

Figure 16 shows the steady-state predictions obtained at the end time of each control cycle for three case studies: (1) No model mismatches - The model used by NMPC is the proposed model with all parameters obtained from the process identification; (2) Case 1 - 

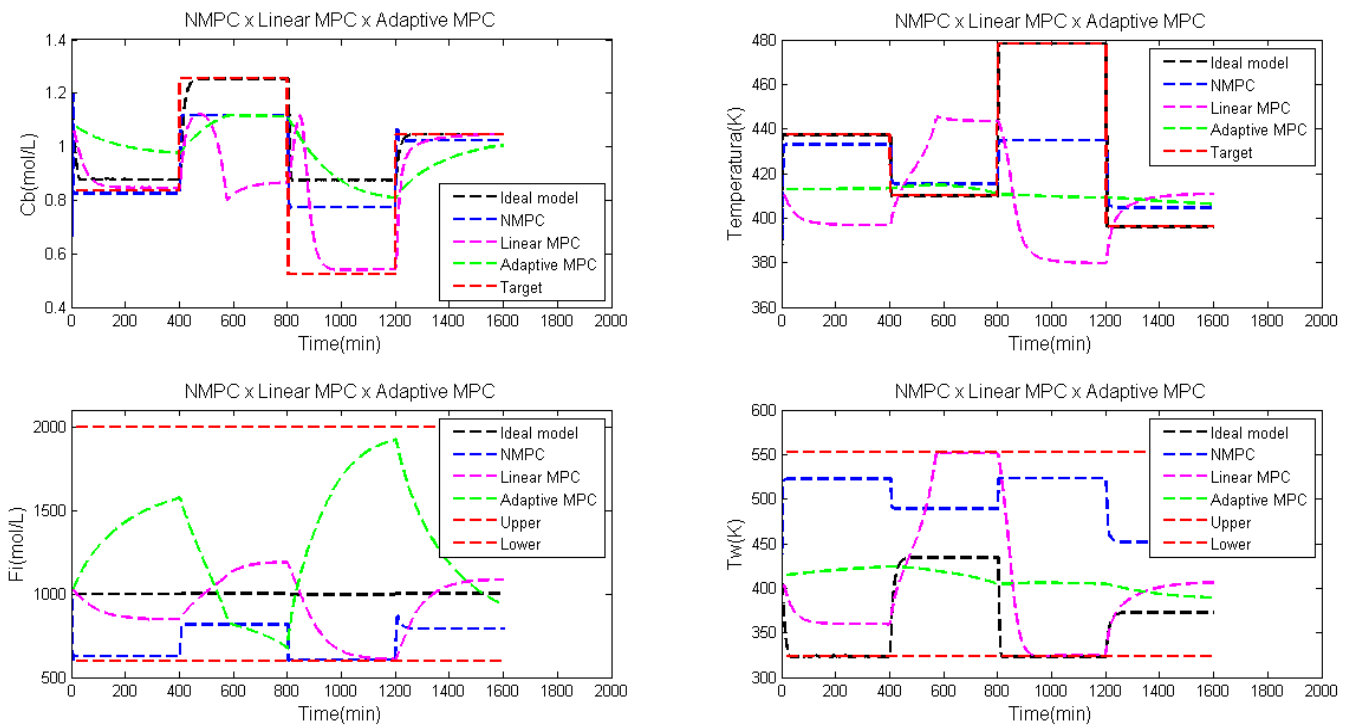

Figure 15. Comparison between the NMPC with the proposed model and an Adaptive MPC.
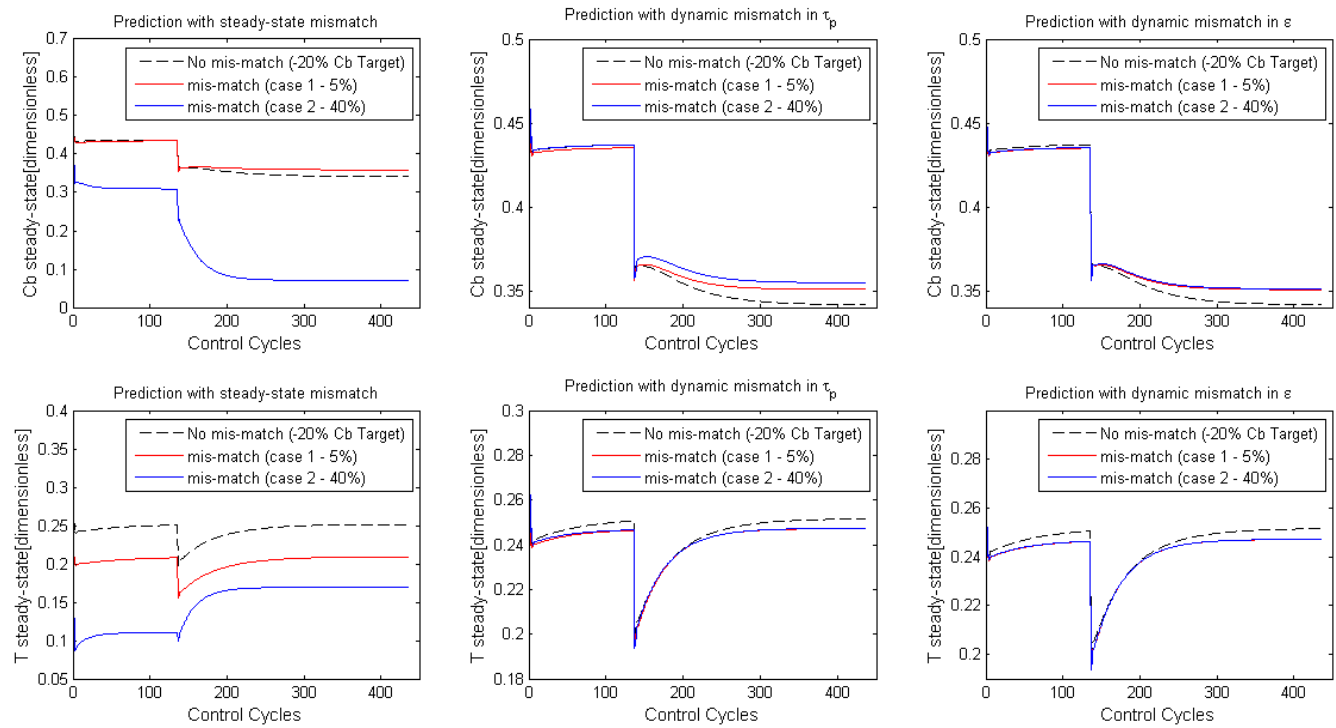

Figure 16. Result of the proposed NMPC with steady-state model mismatches to keep the plant on $C_{b}$ and the temperature setpoint. The controller turned on at time equal to $15 \mathrm{~min}$ and the $C_{b}$ setpoint changed at time equal to $150 \mathrm{~min}$.

Random Model mismatch with a range of variability of 5\% ; (3) Case 2 - Random Model mismatch with a range of variability of $40 \%$. The results illustrate that there is a poor steady-state prediction only for large steady-state model mismatches.

Figure 17 shows the controller performance for steady-state model mismatches. The controller could not drive the plant to the suggested setpoints in case 2, when the range of variability of the model mismatch is $40 \%$. This happens because the controller lost a degree of freedom when the cold fluid Temperature, $T_{w}$, hit the upper bound, leaving the controller with just one manipulated variable to control two controlled variables. Therefore, it is important to obtain accurate models to describe the steady-state nonlinear behavior.
Figures 18 and 19 show the controller performance when there are dynamic model mismatches. The case studies are the same described for steady-state model mismatches, but the parameters with errors are $\tau_{p}$ and $\varepsilon$, respectively. Unlike steady-state model mismatches, where the errors can cause bad control performance and large variability, when the errors are in the dynamic model parameters, there are no performance losses.

Figure 20 shows the NMPC performance with steady-state model mismatches to reject feed composition disturbances. The controller could not drive the plant to the proposed setpoints in case 2 . It happens because the controller lost a degree of freedom when the feed flow rate hit the lower bound, leaving the controller with just one manipulated variable to control two controlled variables. Therefore, the results 

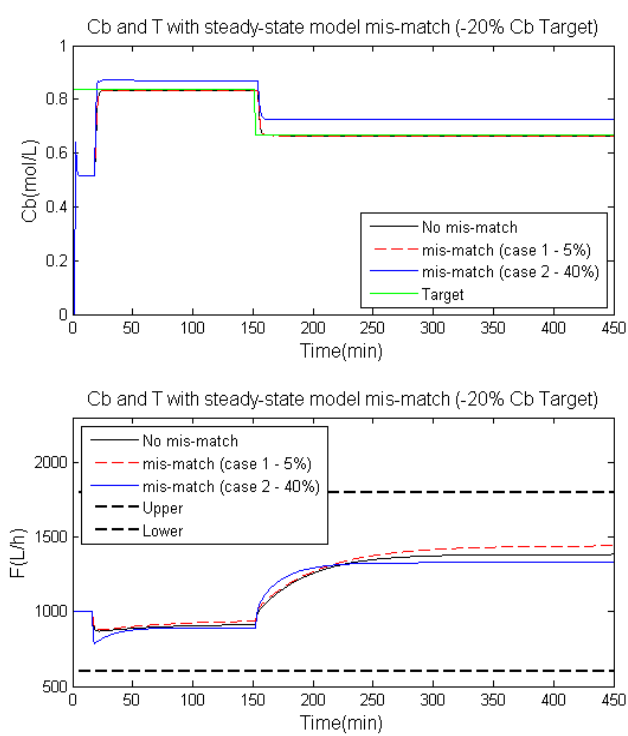
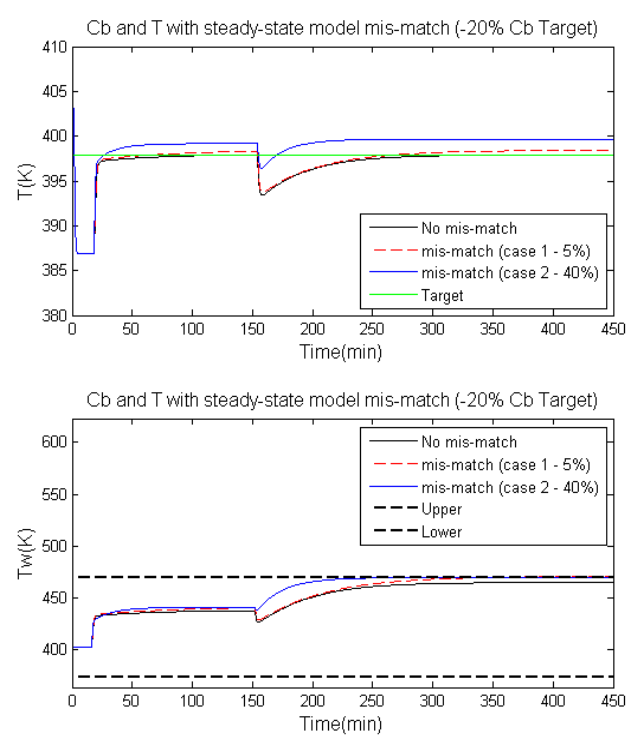

Figure 17. Result of the proposed NMPC with steady-state model mismatches to keep the plant on $C_{b}$ and the temperature setpoint. The controller turned on at time equal to $15 \mathrm{~min}$ and the $C_{b}$ setpoint changed at time equal to $150 \mathrm{~min}$.

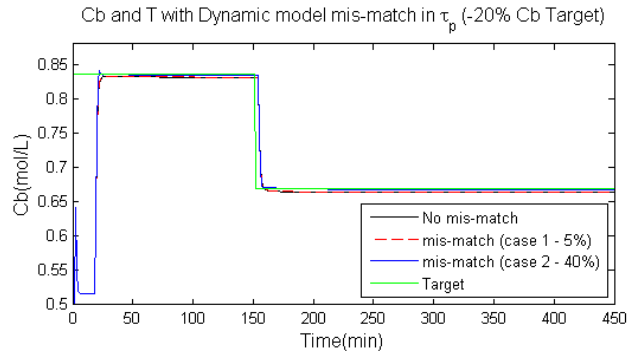

$\mathrm{Cb}$ and T with Dynamic model mis-match in $\tau_{\mathrm{p}}(-20 \% \mathrm{Cb}$ Target $)$

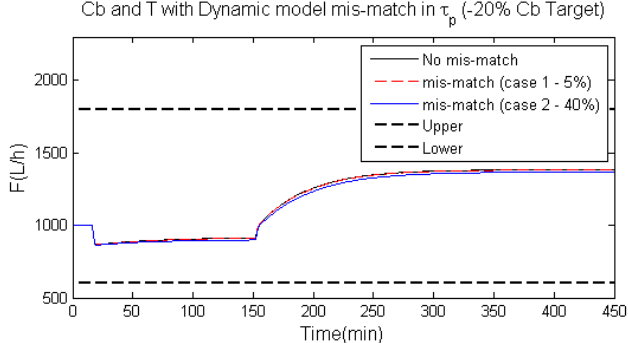

$\mathrm{Cb}$ and $\mathrm{T}$ with Dynamic model mis-match in $\tau_{\mathrm{p}}(-20 \% \mathrm{Cb}$ Target $)$

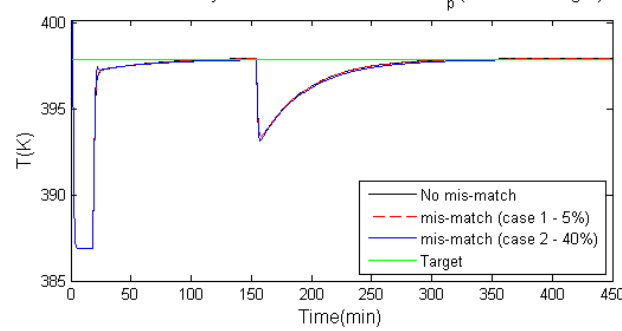

$\mathrm{Cb}$ and T with Dynamic model mis-match in $\tau_{\mathrm{p}}(-20 \% \mathrm{Cb}$ Target $)$

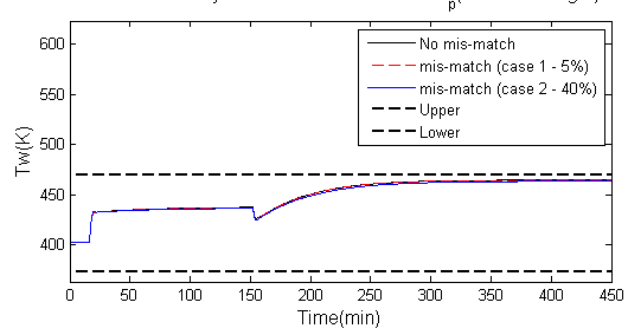

Figure 18. Result of the proposed NMPC with dynamic model mismatches in $\tau_{p}$ to keep the plant on $C_{b}$ and the temperature setpoint. The controller turned on at time equal to $15 \mathrm{~min}$ and the $C_{b}{ }^{p}$ setpoint changed at time equal to $150 \mathrm{~min}$.

illustrate that the proposed NMPC with large steadystate model mismatches cannot carry and keep the controlled variables at setpoints.

Figures 21 and 22 show the proposed NMPC performance to reject the feed composition disturbance when there are dynamic model mismatches in $\tau_{p}$ and $\varepsilon$, respectively. The results illustrate that the model mismatches in the parameters of the dynamic model do not cause performance losses to reject the disturbance.

The proposed NMPC performance to reject an unmeasured disturbance in the cold fluid flow rate

Figure 23 shows the NMPC performance to control $C_{b}$ and the temperature, rejecting an unmeasured disturbance in the cold fluid flow rate. The case studies were done with two kinds of unmeasured disturbance, random and constant, applied at an equal time of 200 $\min$. The results illustrate that the controller rejects the constant disturbance. It happens because the feedback action can eliminate the model mismatches. But, when there is a random unmeasured disturbance in the cold fluid feed flow rate, the controller does not keep the controlled variables at the suggested setpoints, showing bad performance.

\section{NMPC integrated with an optimization layer}

Equations 41 to 47 show the formulation of the optimization problem. The focus is maximizing $C_{b}$ at 

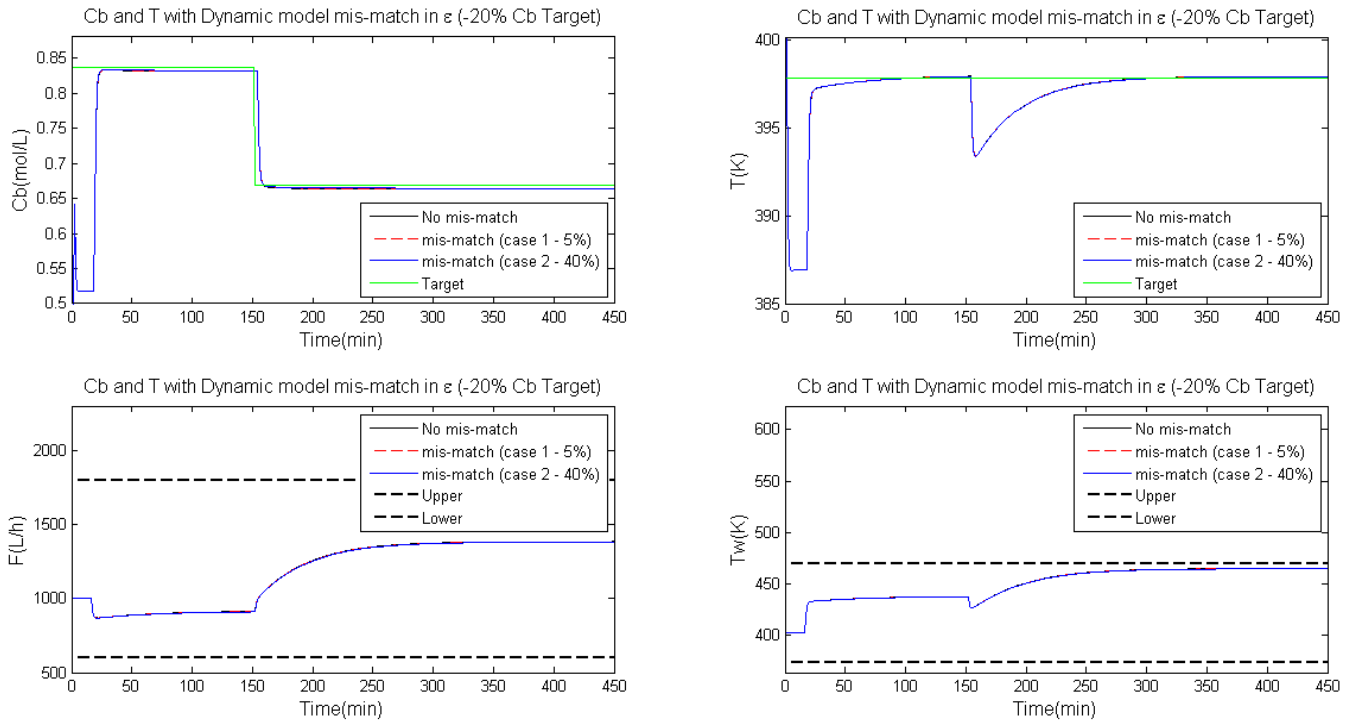

Figure 19. Result of the proposed NMPC with dynamic model mismatches in $\varepsilon$ to keep the plant on $C_{b}$ and the temperature setpoint. The controller turned on at time equal to $15 \mathrm{~min}$ and the $C_{b}$ setpoint changed at time equal to $150 \mathrm{~min}$.
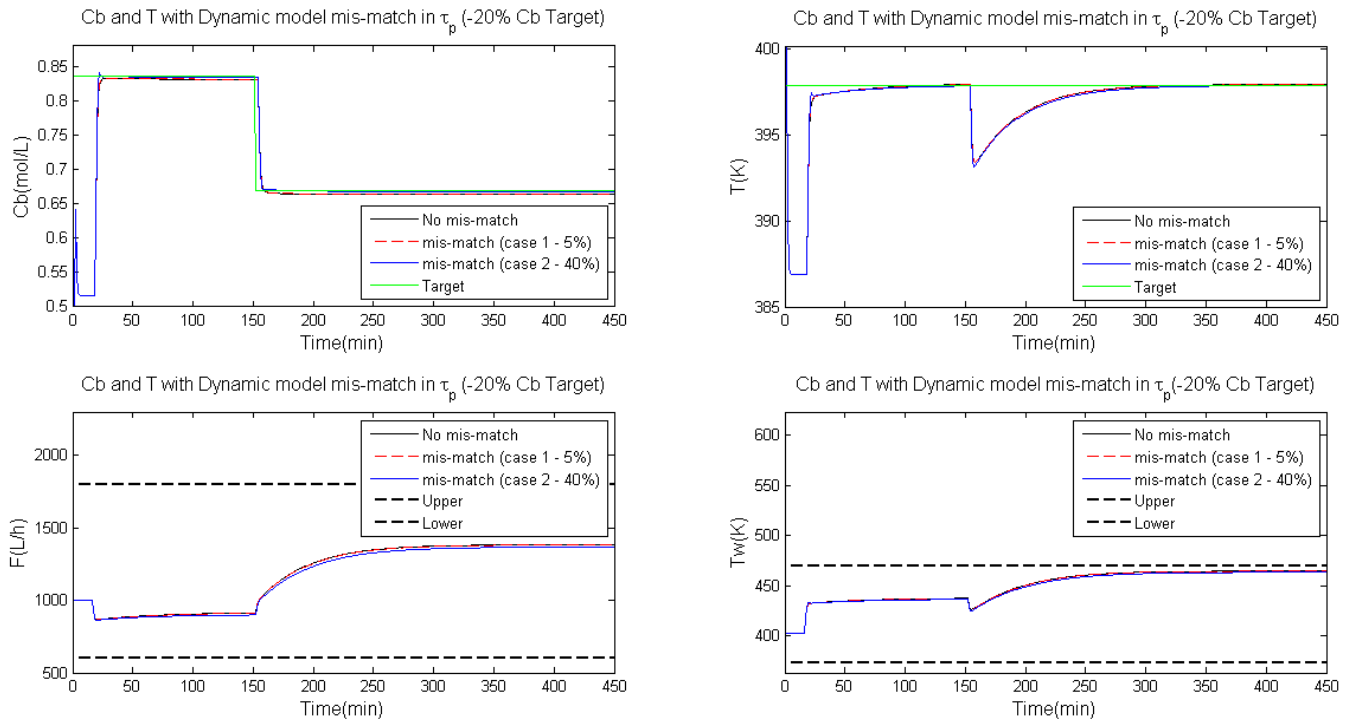

Figure 20. Result of the proposed NMPC with steady-state model mismatches to reject disturbances in feed composition. The controller turned on at time equal to $15 \mathrm{~min}$ and the disturbance happened at time equal to 150 $\min$.

the steady state, sending this setpoint for the control layer represented by Equation 1.

$$
\underset{\underline{u}}{\operatorname{Max}} C_{b}
$$

subject to

$0=\frac{F}{V}\left(C_{a_{\text {in }}}-C_{a}\right)-K_{1}(T) C_{a}-K_{3}(T) C_{a}^{2}$

$0=\frac{F}{V} C_{b}+K_{1}(T) C_{a}-K_{2}(T) C_{b}$

$$
\begin{aligned}
& 0=-\frac{1}{\rho C_{\mathrm{p}}}\left[\mathrm{K}_{1}(\mathrm{~T}) \mathrm{C}_{\mathrm{a}}\left(-\Delta \mathrm{H}_{\mathrm{R}_{\mathrm{AB}}}\right)+\mathrm{K}_{2}(\mathrm{~T}) \mathrm{C}_{\mathrm{b}}\left(-\Delta \mathrm{H}_{\mathrm{R}_{\mathrm{BC}}}\right)+\mathrm{K}_{3}(\mathrm{~T}) \mathrm{C}_{\mathrm{a}}^{2}\left(-\Delta \mathrm{H}_{\mathrm{R}_{\mathrm{AD}}}\right)\right]+ \\
& \frac{\mathrm{F}}{\mathrm{V}}\left(\mathrm{T}_{\mathrm{in}}-\mathrm{T}\right)+\frac{\mathrm{K}_{\mathrm{W}} \mathrm{A}_{\mathrm{R}}}{\rho \mathrm{C}_{\mathrm{P}} \mathrm{V}}\left(\mathrm{T}_{\mathrm{w}}-\mathrm{T}\right)
\end{aligned}
$$

$$
K_{i}(T)=K_{i 0} \exp \left(-\frac{E_{i}}{R T}\right)
$$

$$
\mathrm{u}_{\min } \leq \underline{\mathrm{u}} \leq \mathrm{u}_{\max }
$$

$$
\mathrm{y}_{\min } \leq \underline{\mathrm{y}} \leq \mathrm{y}_{\max }
$$



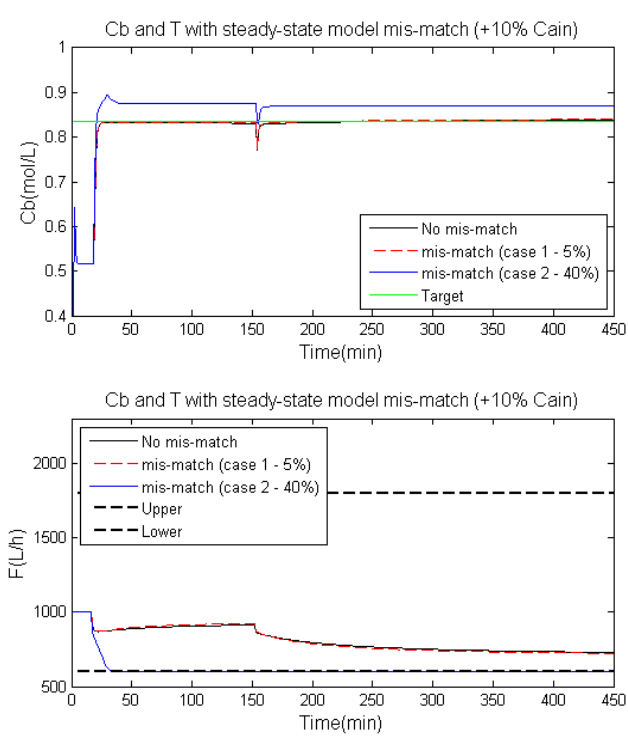
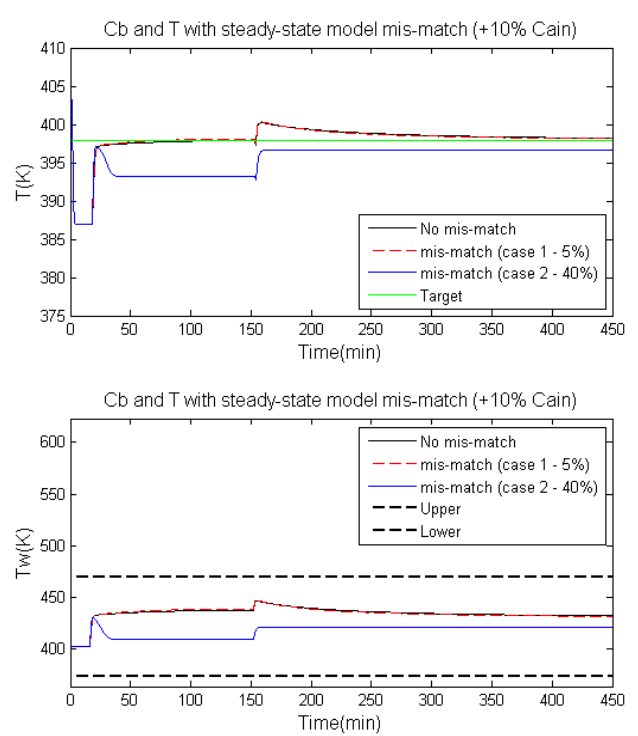

Figure 21. Result of the proposed NMPC with dynamic model mismatches in $\tau_{p}$ to reject disturbances in the feed composition. The controller turned on at time equal to $15 \mathrm{~min}$ and the disturbance happened at time equal to 150 $\min$.
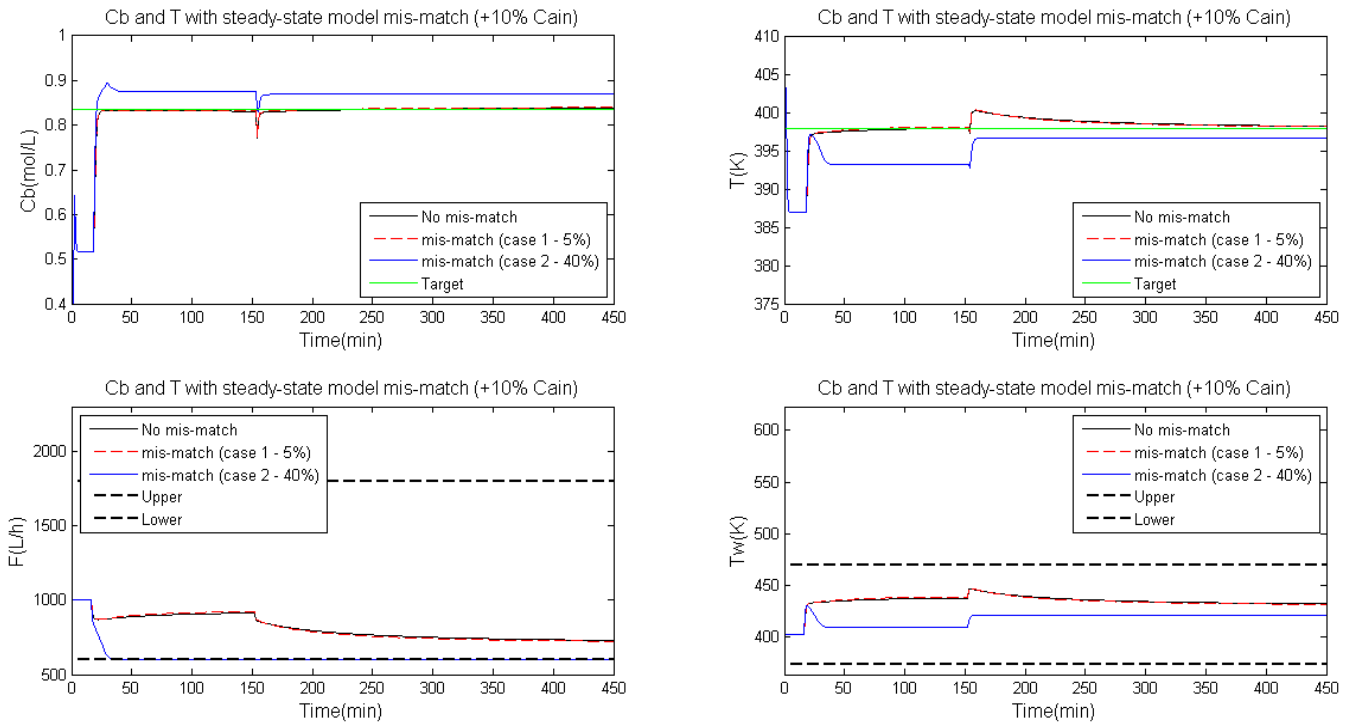

Figure 22. Result of the proposed NMPC with dynamic model mismatches in $\varepsilon$ to reject disturbances in the feed composition. The controller turned on at time equal to $15 \mathrm{~min}$ and the disturbance happened at time equal to 150 $\min$.

where Equations 42 to 44 represent the steady state of the process, while upon replacing these equations by Equations 33 to 35 , the problem is reformulated as a dynamic optimization problem.

The optimization consists of maximizing the $C_{b}$ subject to constraints on the manipulated and controlled variables. Figure 24 shows the good performance of the proposed NMPC to track the setpoint sent by the optimization layer, presenting no offset between them. Moreover, it is important to say that only the first control action is implemented, reducing impacts caused by model mismatches and unmeasured disturbances.

Figures 25 and 26 illustrate a comparison between the optimization using the rigorous model and the proposed model. The optimization with the proposed model shows a reduction of 2.5-fold in the computational time to solve the nonlinear problem without any performance loss, showing that the proposed model can be used for the steady-state optimization.

Figure 27 illustrates the performance of the proposed algorithm integrated with a dynamic optimization layer, where $C_{b}$ is maximized along all paths. The result was compared with the optimization strategy using the steady-state model and with the dynamic optimization without the NMPC layer. According to Table 4, all solutions were close, with the maximum $C_{b}$ obtained by the DRTO+NMPC strategy. The DRTO 

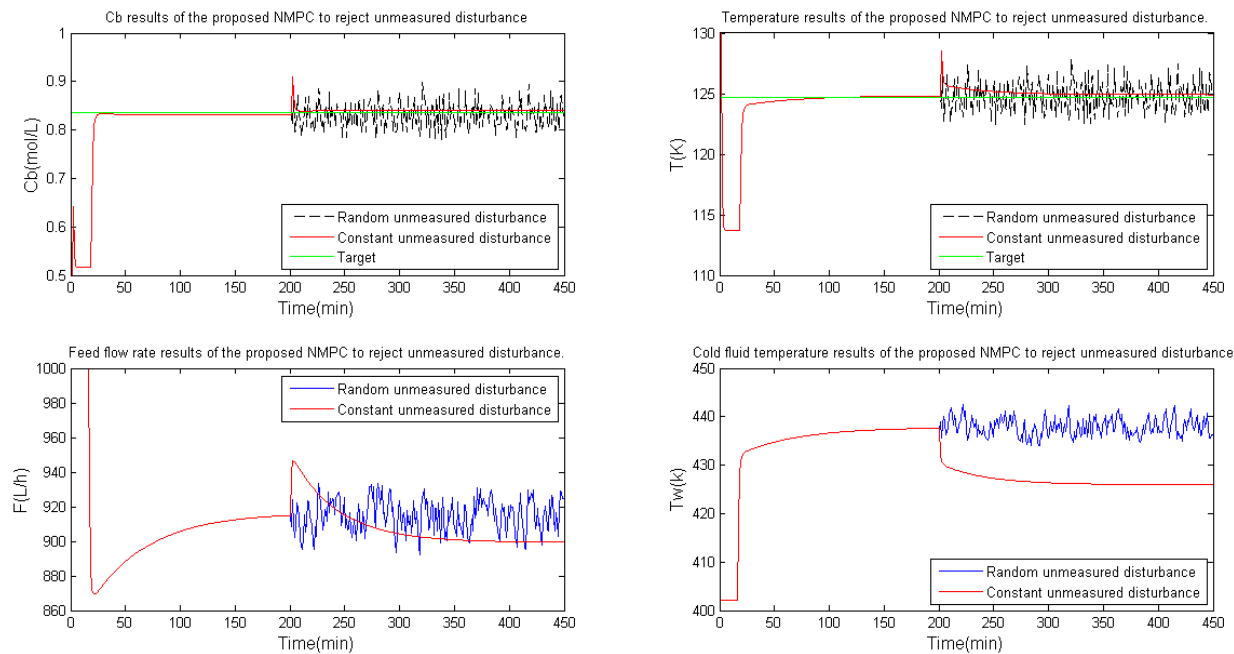

Figure 23. Results of the proposed NMPC to reject unmeasured disturbance in cold fluid flow rate that happened at time equal to $200 \mathrm{~min}$.
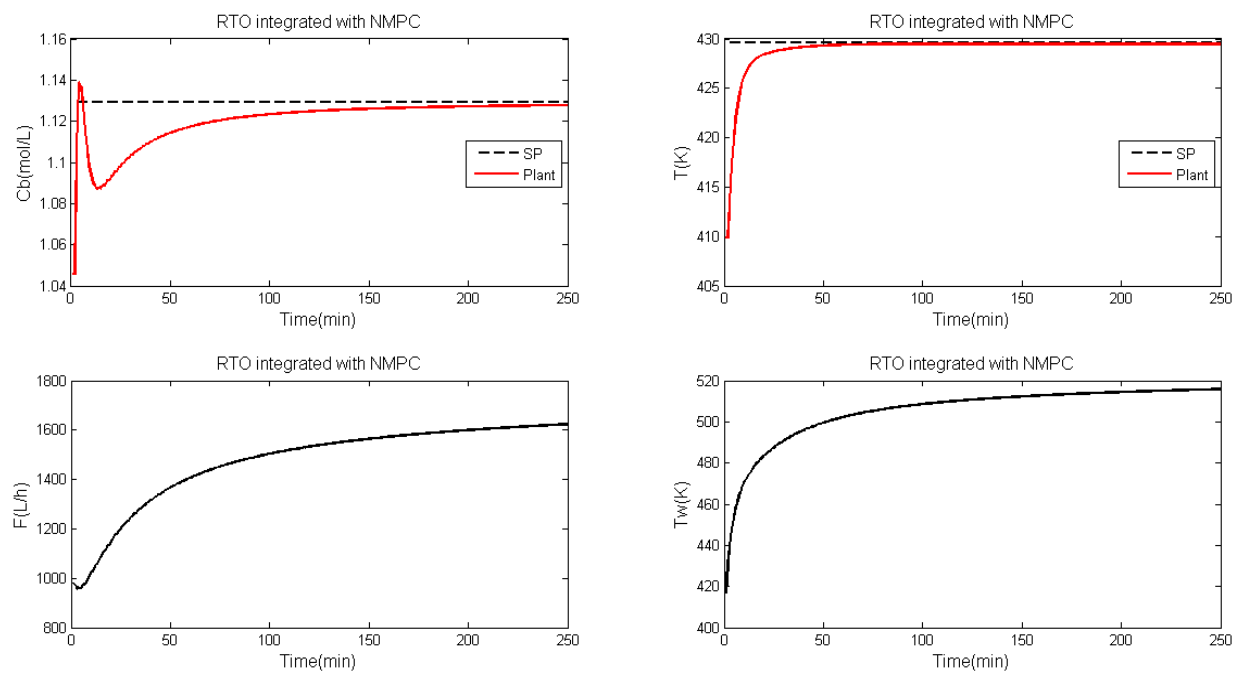

Figure 24. Results of the proposed NMPC with the optimizing layer.
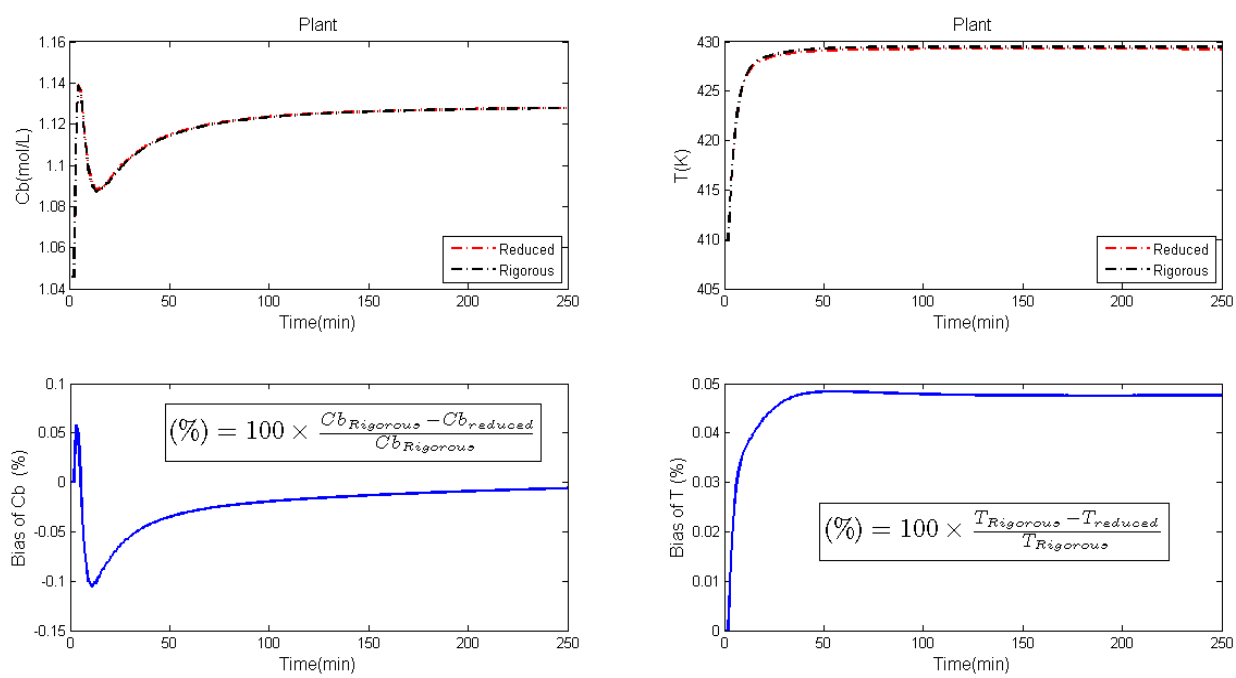

Figure 25. Comparison between the steady-state optimization using the multi-parametric model and the rigorous model. 

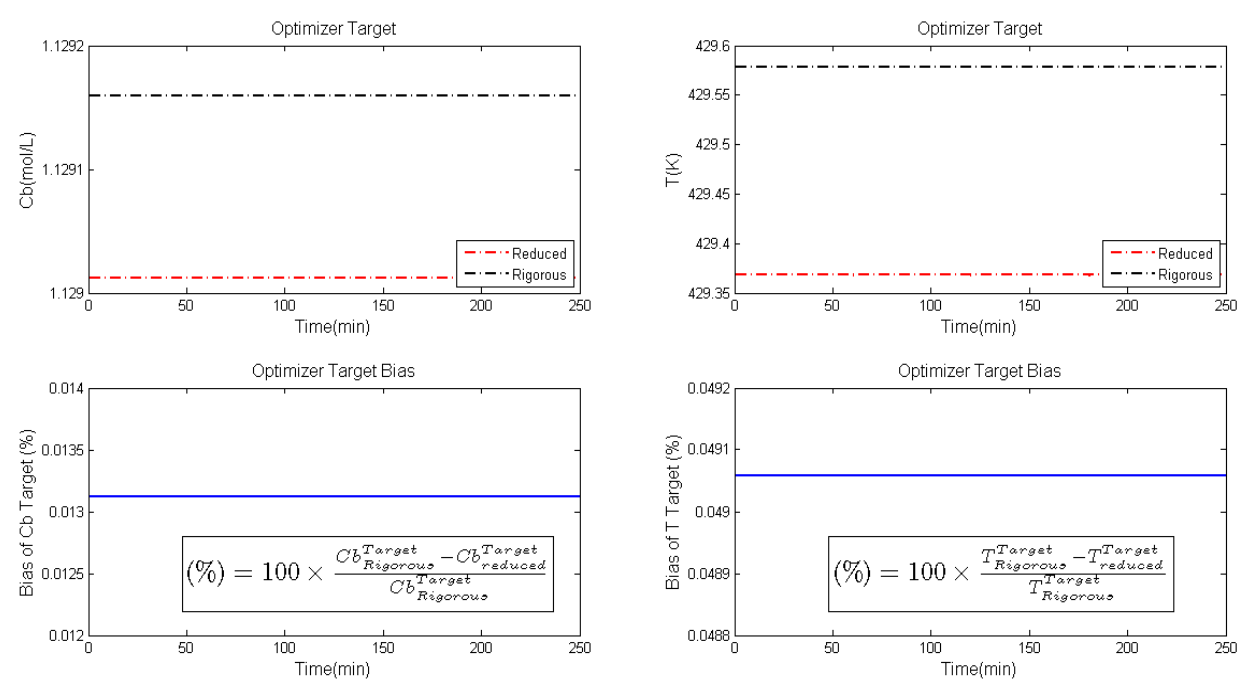

Figure 26. Comparison between the optimizer target using the multi-parametric model and the rigorous model.
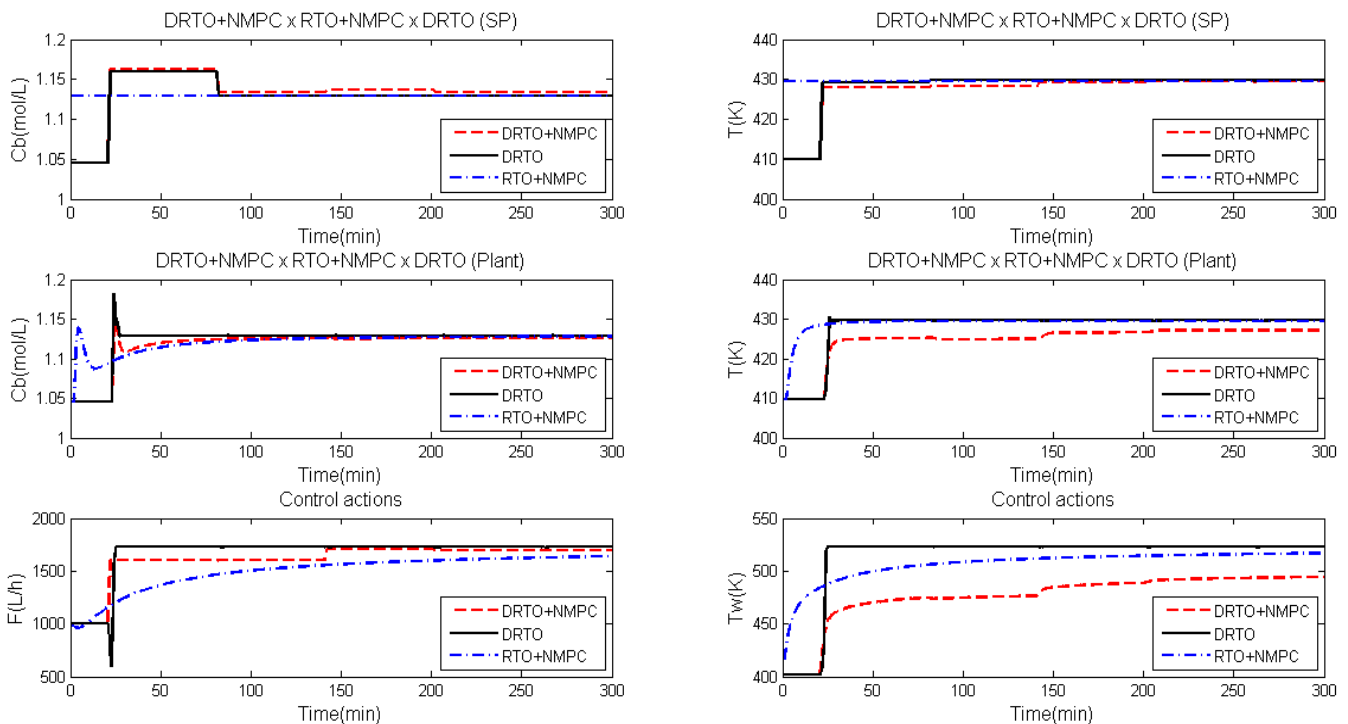

Figure 27. Comparison between the result obtained by dynamic and steady-state optimization.

Table 4. Comparison between the optimization structures.

\begin{tabular}{ccccc}
\hline \multirow{2}{*}{ Approach } & \multicolumn{2}{c}{$\mathbf{C}_{\mathbf{b}} \mathbf{C}_{\mathbf{b} \text { Target }}$} & $\mathbf{T}$ & $\mathbf{T}_{\text {Target }}$ \\
\cline { 2 - 5 } & \multicolumn{2}{c}{$(\mathbf{m o l} / \mathbf{L})$} & \multicolumn{2}{c}{$\mathbf{( K )}$} \\
\hline DRTO & 1.1290 & 1.1308 & 428.31 & 429.37 \\
DRTO + NMPC & 1.1297 & 1.1357 & 427.17 & 429.33 \\
RTO + NMPC & 1.1281 & 1.1293 & 429.44 & 429.57 \\
\hline
\end{tabular}

strategy led the plant to the setpoints faster than the others, but presented a larger overshoot. The results show that the NMPC layer followed the trajectories computed by D-RTO, demonstrating that the D-RTO trajectories are reachable and feasible for the proposed model.

\section{CONCLUSION}

The challenge to apply NMPC strategies is to obtain models that describe the process behavior and whose computational time spent in each control cycle allows a reasonable frequency for industrial applications.

In this context, a methodology to obtain analytical models for NMPC algorithms was proposed, avoiding loss of accuracy caused by numerical approximations. The analytical model reduces the computational complexity faced in real time implementation of NMPC controllers, with great potential to be applied to large-scale problems.

The comparison between the NMPC based on the proposed model and an adaptive NMPC algorithm, where the current steady-state gain is computed online, showed that the proposed NMPC had a better performance to drive the plant to the setpoints, without causing additional computational effort.

There were no model mismatches between the proposed model used in the control layer and the rigorous model present in the optimization layer, ensuring that the optimal trajectory computed in 
the D-RTO layer is reachable and feasible for the controller. The results show that the proposed NMPC was capable of following the optimal trajectories computed in the D-RTO layer, driving the plant to the optimal solution.

\section{REFERENCES}

Aadaleesan, P., Miglan, N., Sharma, R. Nonlinear system identification using Wiener type Laguerrewavelet network model. Chemical Engineering Science, 63, 932-3941 (2008). https://doi. org/10.1016/j.ces.2008.04.043

Akesson, B.M., Toivonen, H.T. A neural network model predictive controller. Journal of Process Control, 16, 937-946 (2006). https://doi.org/10.1016/j. jprocont.2006.06.001

Alangar, A., Durand, H., Christofides, P.D. On identification of well-conditioned nonlinear systems: Application to economic model predictive control of nonlinear processes. AIChE Journal, 61, 3353-3373 (2015a). https://doi.org/10.1002/ aic. 14942

Alangar, A., Ellis, M., Christofides, P.D. Economic model predictive control of nonlinear process systems using empirical models. AIChE Journal, 61, 816-830 (2015b). https://doi.org/10.1002/ aic. 14683

Almeida, E., Secchi, A.R. Solving dynamic optimization infeasibility problems. Computers and Chemical Engineering, 36, 227-246 (2012). https:// doi.org/10.1016/j.compchemeng.2011.07.003

Biegler, L.T. Nonlinear Programming Concepts, Algorithms and Application to Chemical Processes. SIAM, Philadelphia (2010). https://doi. org/10.1137/1.9780898719383

Biegler, L.T., Yang, X., Fischer, G.A.G. Advances in sensitivity-based nonlinear model predictive control and dynamic real-time optimization. Journal of Process Control, 30, 104-116 (2015). https://doi.org/10.1016/j.jprocont.2015.02.001

Bloemen, H.H.J., Chou, C.T., Boom, T.J.J., Verdult, V., Verhaegen, M., Backx, T.C. Wiener model identification and predictive control for dual composition control of a distillation. Journal of Process Control, 11, 601-620 (2001). https://doi. org/10.1016/S0959-1524(00)00056-1

Byrd, R.H., Hribar, M.E., Nocedal, J. An interior point algorithm for large-scale nonlinear programming. SIAM Journal on Optimization, 9, 877-900 (1999). https://doi.org/10.1137/S1052623497325107

Cervantes, A., Agamennoni, O.E., Figueroa, J.L. A nonlinear model predictive control system based on wiener piecewise linear models. Journal of Process Control, 13, 665-666 (2003a). https://doi. org/10.1016/S0959-1524(02)00121-X
Cervantes, A.L., Agamennoni, O.E., Figueroa, J.L. A nonlinear model predictive control system based on wiener piecewise linear model. Journal of Process Control, 13, 665-666 (2003b). https://doi. org/10.1016/S0959-1524(02)00121-X

Diehl, M., Bock, H.G., Schloder, J.P. A real-time iteration scheme for nonlinear optimization in optimal feedback control. SIAM Journal on Control and Optimization, 43, 1714-1736 (2005). https:// doi.org/10.1137/S0363012902400713

Doyle, F.J., Ogunnaike, B.A., Person, R.K. Nonlinear model-based control using a second-order Volterra models. Automatica, 31, 697-714 (1995). https:// doi.org/10.1016/0005-1098(94)00150-H

Duraiski, R.G., Trierweiler, J.O., Secchi, A.R. Nonlinear model predictive control using successive linearization approach. In: Proceedings of the 3rd Mercosur Congress on Process Systems Engineering (ENPROMER 2001). 1, 301-306 (2001).

Eaton, A.N., Beal, L.D.R., Thorpe, S.D. Realtime identification using multi-fidelity models in managed pressure drilling. Computers and Chemical Engineering, 97, 76-84 (2017). https:// doi.org/10.1016/j.compchemeng.2016.11.008

Ellis, M., Christofides, P.D. Real-time economic model predictive control of nonlinear process systems. AIChE Journal, 61, 555-571 (2015). https://doi. org/10.1002/aic.14673

Garcia, C.E., Morshedi, A.M. Quadratic programming solution of dynamic matrix control (QDMC). Chemical Engineering Communication, 46, 73-87 (1986). https://doi. org/10.1080/00986448608911397

Gomez, J.C., Jutan, A., Baeyens, E. Wiener model identification and predictive control of a phneutralisation process. IEE Proceedings Part D: Control Theory and Applications, 151, 329-338 (2004). https://doi.org/10.1049/ip-cta:20040438

Henson, M.A. A nonlinear model predictive control: Control status and future directions. Computers and Chemical Engineering, 23, 187-202 (1998). https://doi.org/10.1016/S0098-1354(98)00260-9

Horn, R. Topics in Matrix Analysis. Cambridge University Press (1994).

Huang, R., Patwardhan, S.C., Biegler, L.T. Robust stability of nonlinear model predictive control based on extender Kalman-fillter. Journal of Process Control, 22, 82-89 (2012). https://doi. org/10.1016/j.jprocont.2011.10.006

Inga, J., Marquardt, W. Fast NMPC scheme for regulatory and economic NMPC - a review. Journal of Process Control, 44, 162-183 (2016). https://doi. org/10.1016/j.jprocont.2016.05.002

Janczak, A. Identification of Nonlinear Systems Using Neural Networks and Polynomial Models. A BlockOriented Approach Lecture Notes in Control and Information Science. Vol. 310. Springer (2004). https://doi.org/10.1007/b98334 
Jaschke, J., Yang, X., Biegler, L.T. Fast economic model predictive control based on NLP-sensitivities. Journal of Process Control, 24, 1260-1272 (2014). https://doi.org/10.1016/j.jprocont.2014.04.009

Kalafatis, A.D., Wang, L., Cluett, W.R. Linearizing feedforward-feedback control of $\mathrm{pH}$ processes based on wiener model. Journal of Process Control, 15, 103-112 (2005). https://doi.org/10.1016/j. jprocont.2004.03.006

Khani, F., Haeri, M. Robust model predictive control of nonlinear processes represented by wiener or hammerstein models. Chemical Engineering Science, 129, 223-231 (2015). https://doi. org/10.1016/j.ces.2015.02.021

Klatt, K.U., Engell, S. Gain-scheduling trajectory control of a continuous stirred tank reactor. Computers and Chemical Engineering, 22, 491502 (1998). https://doi.org/10.1016/S00981354(97)00261-5

Knohl, T., Unbehauen, H. Adaptive position control of electrohydraulic servo system using ann. Mechatronics, 10, 127-143 (2000). https://doi. org/10.1016/S0957-4158(99)00054-9

Lawrynczuk, M. A family of model predictive control algorithms with artificial neural networks. International Journal of Applied Mathematics and Computer Science, 17, 217-232 (2007). https://doi. org/10.2478/v10006-007-0020-5

Lawrynczuk, M. Computationally efficient nonlinear predictive control based on neural Wiener models. Neurocomputing, 74, $401-417$ (2010). https://doi. org/10.1016/j.neucom.2010.03.014

Lawrynczuk, M. Practical nonlinear predictive control algorithms for neural Wiener models. Journal of Process Control, 23, 696-714 (2013). https://doi. org/10.1016/j.jprocont.2013.02.004

Li, W., Biegler, L.T. Multistep, Newton-type control strategies for constrained, nonlinear processes. Chemical Engineering Research and Design, 562-577 (1989). https://doi.org/10.23919/ ACC.1989.4790428

Lopez-Negrete, R., Biegler, L.T., Kumar, A. Fast nonlinear model predictive control: Formulation and industrial process applications. Computers and Chemical Engineering, 51, 55-64 (2013). https:// doi.org/10.1016/j.compchemeng.2012.06.011

Marti, R., Lucia, S., Sarabia, D. Improving scenario decomposition algorithms for robust nonlinear model predictive control. Computers and Chemical Engineering, 79, 30-45 (2015). https://doi. org/10.1016/j.compchemeng.2015.04.024

Norquay, S.J., Palazoglu, A., Romagnoli, J.A. Model predictive control based on Wiener models. Engineering Science, 53, 75-84 (1998). https://doi. org/10.1016/S0009-2509(97)00195-4
Norquay, S.J., Palazoglu, A., Romagnoli, J.A. Application of Wiener model predictive control (WMPC) to an industrial c2-splitter. Journal of Process Control, 9, 461-473 (1999). https://doi. org/10.1016/S0959-1524(99)00036-0

Pajunen, G. Adaptive control of Wiener type nonlinear systems. Automatica, 28, 781-785 (1992). https:// doi.org/10.1016/0005-1098(92)90037-G

Pearson, R.K., Pottmann, M. 20. Gray-box identification of block-oriented nonlinear models. Journal of Process Control, 10, 301-315 (1992). https://doi.org/10.1016/S0959-1524(99)00055-4

Peng, J., Dubay, R., Hernandez, J.M., Abu-Ayyad, M. A Wiener neural network-based identification and adaptive generalized predictive control for nonlinear SISO systems. Industrial and Engineering Chemistry Research, 50, 7388-7397 (2011). https:// doi.org/10.1021/ie102203s

Pirnay, H., Lopez-Negrete, R., Biegler, L.T. Optimal sensitivity based on IPOPT. Mathematical Programming Computation, 4, 307-331 (2012). https://doi.org/10.1007/s12532-012-0043-2

Rashid, M.M., Mhaskar, P., Swartz, C.L.E. Multi-rate modeling and economic model predictive control of the electric arc furnace. Journal of Process Control, 40, 50-61 (2016). https://doi.org/10.1016/j. jprocont.2015.12.012

Rodriguez, M., Perez, D. First principles model based control. Computer Aided Chemical Engineering, 20, 1285-1290 (2005). https://doi.org/10.1016/ S1570-7946(05)80056-2

Seyab, R.K.A., Cao, Y. Nonlinear model predictive control for the Alstom gasifier. Journal of Process Control, 16, 795-808 (2006). https://doi. org/10.1016/j.jprocont.2006.03.003

Sriniwas, G.R., Arkun, Y. A global solution to the nonlinear predictive control algorithms using polynomial ARX models. Computers and Chemical Engineering, 21, 431-439 (1997). https://doi. org/10.1016/S0098-1354(96)00279-7

Stamnes, O.N., Zhou, J., Aamo, O.M. Adaptive observer design for the bottom hole pressure of a managed pressure drilling system. In: IEEE Conference on Decision and Control (2008). https://doi.org/10.1109/CDC.2008.4738845

Tatjewski, P. Advanced Control of Industrial Process, Structure and Algorithms. Springer (2007).

Trierweiler, J.O. A systematic approach to control structure design. Ph.D. Thesis, Dortmund University (1997).

Trierweiler, J.O., Secchi, A.R. Exploring the potentiality of using multiple model approach in nonlinear model predictive control. In: Allgower, F., Zhen, A. (Eds.), Nonlinear Model Predictive Control. Birkhauser Verlag, 26, 191-203 (2000). https://doi.org/10.1007/978-3-0348-8407-5_11 
Wang, X., Mahalec, V., Qian, F. Globally optimal dynamic real time optimization without model mismatch between optimization and control layer. Computers and Chemical Engineering, 104, 64-75 (2017). https://doi.org/10.1016/j. compchemeng.2017.04.006

Yang, X., Biegler, L.T. Advanced-multi-step nonlinear model predictive control. Journal Process Control, 23, 1116-1128 (2013). https://doi.org/10.1016/j. jprocont.2013.06.011

Zanin, A.C., Gouvea, M.T.D., Odloak, D. Industrial implementation of a real-time optimization strategy for maximizing production of LPG in a FCC unit. Computers and Chemical Engineering, 24, 525-531 (2000). https://doi.org/10.1016/S00981354(00)00524-X

Zavala, V.M., Biegler, L.T. Optimization-based strategies for the operation of low-density polyethylene tubular reactors: Nonlinear model predictive control. Computers and Chemical Engineering, 33, 1735-1746 (2009). https://doi. org/10.1016/j.compchemeng.2009.04.008

\section{APPENDIX A. DEVELOPMENT OF THE STEADY-STATE MODEL}

Figure A.28 shows the relationship between the manipulated and disturbance variables with the controlled variables, illustrating how the multiparametric model was built to represent the steadystate conditions. The procedure used to obtain the multi-parametric model was: (1) All disturbances are kept constant and steps in the manipulated variables are done. Therewith, it is possible to get a polynomial function that describes the relationship of manipulated variables with the controlled variables; (2) After that, each disturbance changes at a time, and again the polynomials are gotten; (3) So, the parameters of polynomial functions, gotten in step one, can be described as functions of the disturbance variables.

\section{APPENDIX B. DEVELOPMENT OF THE DYNAMIC MODEL}

Considering that a linear model can describe the process dynamic behavior and a nonlinear model can represent the steady state, it is possible to describe the process by a structure based on Hammerstein models, as shown in Figure B.29 and illustrated in Equations 6 to 9 in Section 2.

In this context, a second order model was chosen as the dynamic model because this structure can describe the dynamic behavior of the case study, as illustrated in Figures 3 and 4, and many other dynamic systems in chemical processes. In Equation B.1, the steady state nonlinearity is represented by $v(\underline{u})$ inputs.

Equation B.1 shows a linear dynamic system represented by a second order model:

$$
\begin{aligned}
& \tau^{2} \frac{d^{2} \bar{y}}{d t}+2 \varepsilon \tau \frac{d \bar{y}}{d t}+\bar{y}=\bar{v} \\
& \underset{\mathrm{u}}{\mathrm{C}} \mathrm{C}(\cdot) \mathrm{H}_{\bar{v}}^{\text {Static map }}
\end{aligned}
$$

Figure B.29. Hammerstein Model.
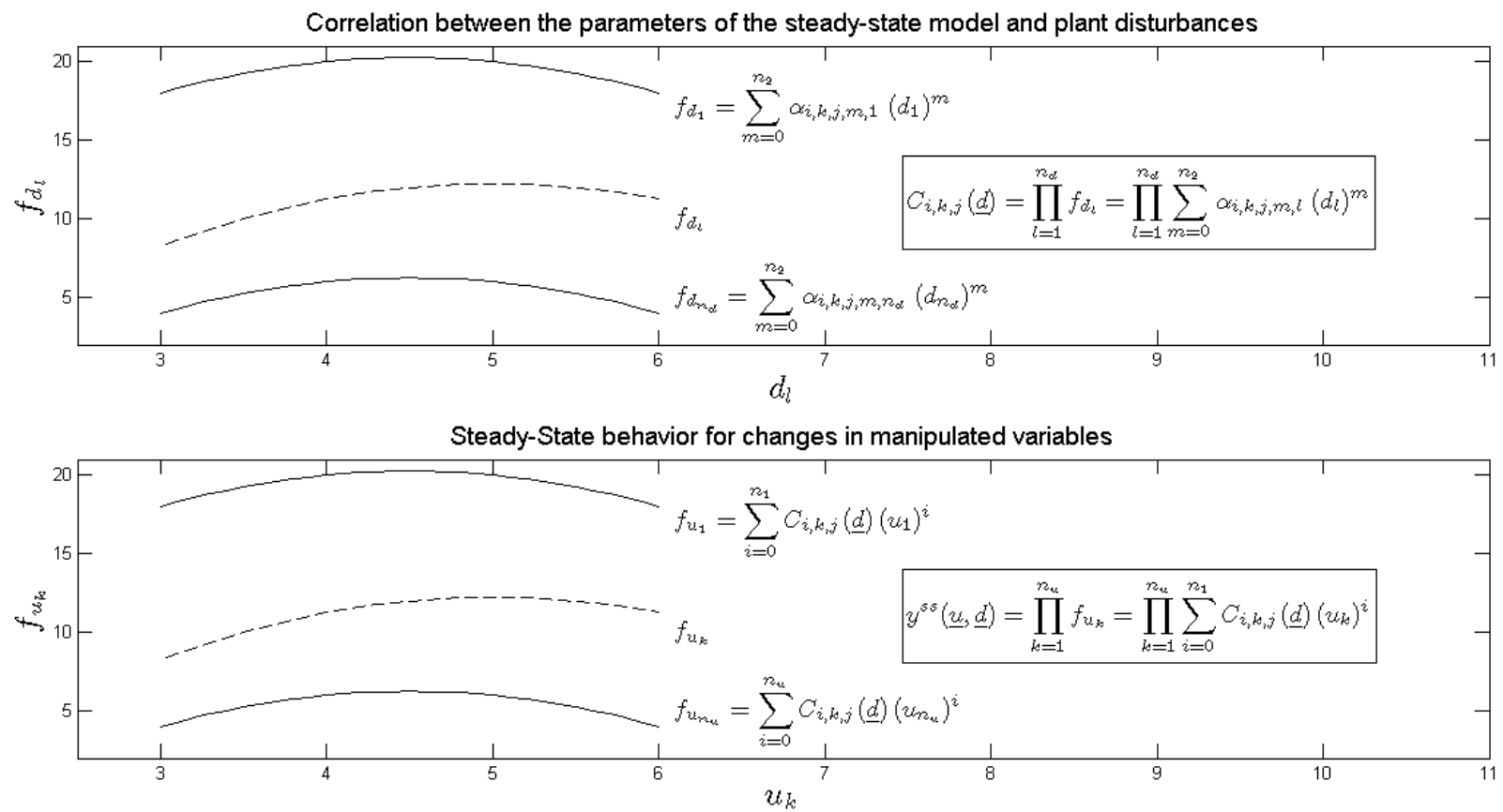

Figure A.28. The multi-parametric model representation to describe the steady-state conditions. 
where

$\bar{y}(t)=y(t)-y(0)$

$\overline{\mathrm{v}}(\underline{\mathrm{u}})=\mathrm{y}^{\mathrm{ss}}(\underline{\mathrm{u}})-\mathrm{y}(0)$

Applying the Laplace transform in Equation B.1, for a constant $\underline{u}$ :

$\hat{\mathrm{Y}}(\mathrm{s})=\frac{\mathrm{y}^{\mathrm{ss}}(\underline{\mathrm{u}})-\mathrm{y}(0)}{\mathrm{s}\left(\tau^{2} \mathrm{~s}^{2}+2 \varepsilon \tau \mathrm{s}+1\right)}$

and in the time domain:

$\mathrm{y}(\mathrm{t})=\mathrm{y}(0)+\left(\mathrm{y}^{\mathrm{ss}}(\underline{\mathrm{u}})-\mathrm{y}(0)\right)\left(1-\frac{\tau_{1} \exp \left(-\frac{\mathrm{t}}{\tau_{1}}\right)-\tau_{2} \exp \left(-\frac{\mathrm{t}}{\tau_{2}}\right)}{\tau_{1}-\tau_{2}}\right)$

where

$\tau_{1}=\frac{\tau}{\varepsilon-\sqrt{\varepsilon^{2}-1}}$

$\tau_{2}=\frac{\tau}{\varepsilon+\sqrt{\varepsilon^{2}-1}}$

Substituting Equations B.3 and B.4 in Equation B.2 and assuming that there is a dead time, $\tau_{d}$, we have:

$\underline{y}(t)=\underline{y}^{0}+\left[\underline{y}^{s s}(\underline{u}, \underline{d})-\underline{y}^{0}\right] \underline{f}(t)$

where

$f(t)=1-\exp \left[\frac{-\varepsilon\left(t-\tau_{d}\right)}{\tau}\right]\left\{\cosh \left[\frac{\sqrt{\varepsilon^{2}-1}}{\tau}\left(t-\tau_{d}\right)\right]+\right.$

$\left.\frac{\varepsilon}{\sqrt{\varepsilon^{2}-1}} \sinh \left[\frac{\sqrt{\varepsilon^{2}-1}}{\tau}\left(\mathrm{t}-\tau_{\mathrm{d}}\right)\right]\right\}$

Equation B.6 can describe a first order system when $\varepsilon \rightarrow 1, \tau \gg>1$ and $\tau_{d}=0$. Replacing these parameter values and rewriting Equation B.6 results in Equation B.9.

Equation B.7 shows a linear dynamic system represented by a first-order model (ODE - Ordinary Differential Equation):

$\tau \frac{\mathrm{dy}}{\mathrm{dt}}+\overline{\mathrm{y}}=\bar{v}$ where

$$
\begin{aligned}
& \bar{y}(t)=y(t)-y(0) \\
& \bar{v}(\underline{u})=y^{s s}(\underline{u})-y(0)
\end{aligned}
$$

Applying the Laplace transform to Equation B.7, for a constant $\underline{u}$ :

$\hat{\mathrm{Y}}(\mathrm{s})=\frac{\mathrm{y}^{\mathrm{ss}}(\underline{\mathrm{u}})-\mathrm{y}(0)}{\mathrm{s}(\tau \mathrm{s}+1)}$

and in the time domain:

$$
\begin{aligned}
& y(t)=y(0)+\left[y^{s s}(\underline{u})-y(0)\right]\left[1-\exp \left(-\frac{t}{\tau}\right)\right] \\
& y(t)=y(0)+\left[y^{s s}(\underline{u})-y(0)\right] f(t)
\end{aligned}
$$

where the time-varying function for a dynamic behavior described by a first-order model is given by:

$$
f(t)=\left[1-\exp \left(-\frac{t}{\tau}\right)\right]
$$

Therefore, it is possible to describe many chemical processes with the structure illustrated by Equation 6 in Section 2, where $y^{S S}$ represents the steady-state and $f(t)$ describes the dynamics. These functions can be obtained from system responses to step changes applied in manipulated variables. For the case study presented in this paper, Equations 7 and 8 in Section 2 represent the steady-state condition and Equation 9 in the same section describes the dynamic behavior.

Figure B.30 shows dynamics that the proposed model can describe. For instance, second-order systems with and without dead time, underdamped or overdamped, and first-order systems. Therefore, it is possible to describe the dynamic behavior of the case study or another system that has similar dynamic behavior. The parameter estimation of the proposed dynamic model was done by minimization of the sum of differences between the responses of the plant and the proposed model, Equation B.10. The performance of the proposed model with the estimated parameters from the minimization of Equation B.10 was successful and is illustrated in Figures 3 and 4.

$$
\min _{\underline{\theta}} \sum_{\mathrm{k}=0}^{\mathrm{n}}\left(\hat{\mathrm{y}}\left(\underline{\mathrm{u}}\left(\mathrm{t}_{\mathrm{k}}\right), \underline{\mathrm{d}}\left(\mathrm{t}_{\mathrm{k}}\right), \underline{\theta}\right)-\mathrm{y}\left(\underline{\mathrm{u}}\left(\mathrm{t}_{\mathrm{k}}\right), \underline{\mathrm{d}}\left(\mathrm{t}_{\mathrm{k}}\right), \underline{\theta}\right)\right)^{2}
$$

where $\hat{y} \in \mathfrak{R}^{n}$ represents the process behavior, $y \in \mathfrak{R}^{n}$ represents the proposed model, $\underline{u}\left(t_{k}\right) \in \mathfrak{R}^{n} u$ and $\underline{d}\left(t_{k}\right) \in$ 


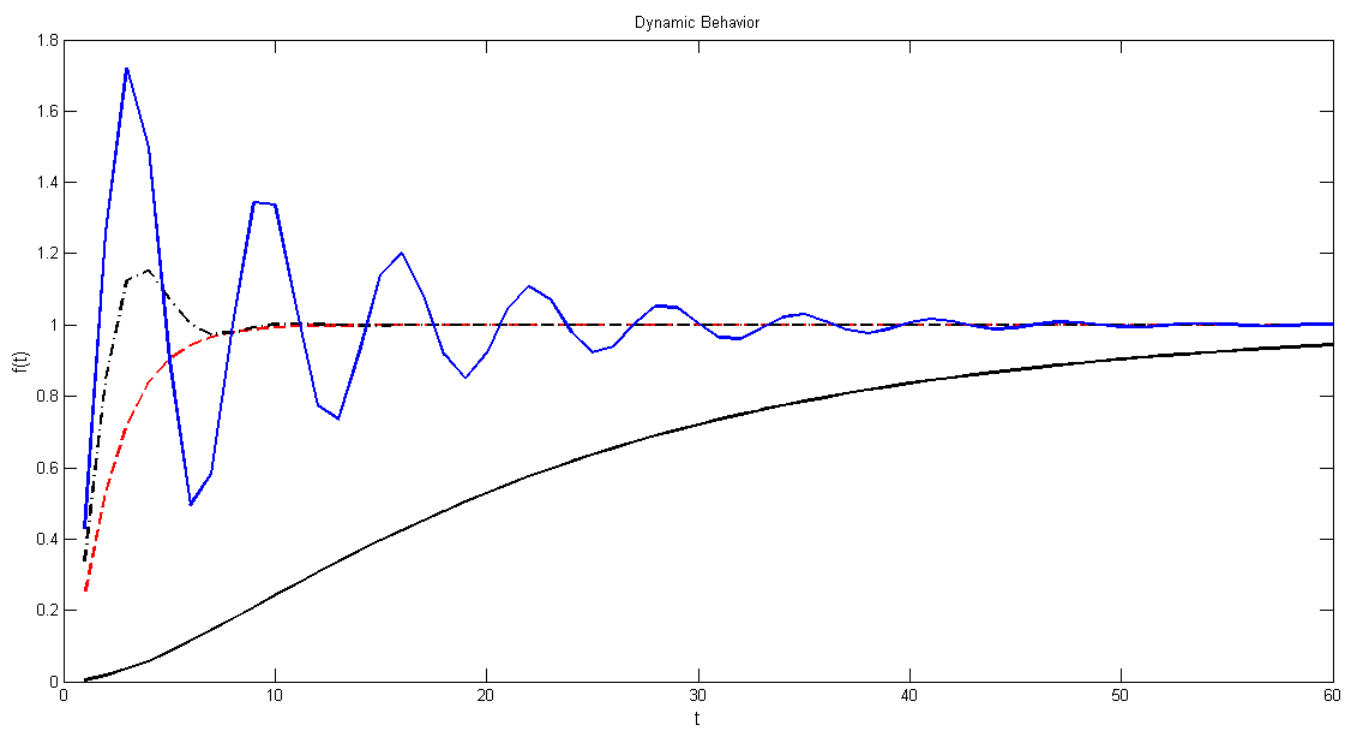

Figure B.30. Dynamics that can be described by the proposed dynamic model.

$\Re^{n} d$ are controlled and disturbance signals, respectively, and $\underline{\theta}=\left[\varsigma, \tau, \tau_{d}\right]$ are the estimated parameters of the dynamic model.

\section{APPENDIX C. HADAMART PRODUCT DEFINITION (Horn, 1994)}

Let $\mathrm{A}$ and $\mathrm{B}$ be $n \times m$ matrices, the Hadamard product, $A \otimes B$, is a matrix of the same dimension as the operands, with elements given by Equation C.1.

$(\mathrm{A} \otimes \mathrm{B})_{\mathrm{i}, \mathrm{j}}=(\mathrm{A})_{\mathrm{i}, \mathrm{j}}(\mathrm{B})_{\mathrm{i}, \mathrm{j}}, \quad$ for all $1 \leq \mathrm{i} \leq \mathrm{m}$ and $1 \leq \mathrm{j} \leq \mathrm{n}(\mathrm{C} .1)$

If $A$ is a $n \times m$ matrix and $B$ is a $p \times q$ matrix, where $m \neq p$ or $n \neq q$, the Hadamard product does not exist. 